\title{
Alfa-Bisabolol: uma revisão de propriedades bioativas antiflogísticas
}

\author{
Alpha-Bisabolol: a review of bioactive properties antiphlogistic \\ Alfa-Bisabolol: una revisión de las propiedades bioactivas antiflogístico
}

\section{Resumo}

O presente trabalho objetivou identificar e sistematizar obras científicas que atribuem ao alfa-bisabolol (BISA) atividades antiflogísticas. Trata-se de uma revisão bibliográfica, cuja seleção dos artigos foi realizada nas bases de dados PubMed, Web of Science e Science Direct. Para fins de coleta de dados foi utilizado as diretrizes PRISMA e o método de Bardin. A estratégia de pesquisa identificou 257 artigos que após triagem foram elegíveis para a revisão 37. Os critérios de inclusão definidos foram: artigos originais, artigos de revisão, pesquisa experimental, ensaios clínicos, in vitro, in vivo e in silico, estudos de meta-análise, na língua inglesa, espanhola e portuguesa. Somente trabalhos com textos completos, acessíveis e na linha do tempo do estudo (janeiro de 2008 a julho de 2021), foram utilizados. Literaturas em duplicata, pagas e que não se relacionavam com o objetivo da pesquisa, foram excluídas. Em relação a abordagem com temáticas específicas temos que: $22(59.45 \%)$ artigos se referem aos efeitos anti-inflamatório, antioxidante e analgésico do BISA, $1(2.70 \%)$ publicação de revisão e $14(37.83 \%)$ investigam as ações do sesquiterpeno sobre o tecido tegumentar. De todos os estudos selecionados $89.18 \%(\mathrm{n}=33)$ foram realizados em ambiente laboratorial e apenas $10.82 \%(\mathrm{n}=4)$ utilizaram outra fonte metodológica. Atualmente há poucas evidências que relatam estudos seguros em preparações tegumentares que utilizam o BISA. Entretanto, os estudos disponíveis sobre as ações antiflogísticas do BISA, comprovam sua eficácia anti-inflamatória, analgésica e antioxidante. Sendo assim, os autores consideram que o sesquiterpeno apresenta potencial clínico para ser utilizado em processos inflamatórios de distintas etiologias, porém são necessárias maiores investigações.

Palavras-chave: Óleos essenciais; BISA; Inflamação; Compostos fitoquímicos.

\begin{abstract}
The present work aimed to identify and systematize scientific works that attribute to alpha-bisabolol (BISA) antiphlogistic activities. This is a literature review, whose selection of articles was carried out in the PubMed, Web of Science, and Science Direct databases. For data collection purposes, the PRISMA guidelines and the Bardin method were used. The search strategy identified 257 articles that after screening were eligible for the review 37 . The inclusion criteria defined were: original articles, review articles, experimental research, clinical trials, in vitro, in vivo and silico, meta-analysis studies, in English, Spanish and Portuguese language. Only works with full texts, accessible and in the study timeline (January 2008 to July 2021) were used. Duplicate literature, paid and unrelated to the research objective, was excluded. Regarding the approach with specific themes, we have that: $22(59.45 \%)$ articles refer to the anti-inflammatory, antioxidant, and analgesic effects of BISA, $1(2.70 \%)$ review publication and 14 $(37.83 \%)$ investigate the actions of sesquiterpene on the integumentary tissue. Of all selected studies, $89.18 \%(\mathrm{n}=33)$ were carried out in a laboratory environment and only $10.82 \%(n=4)$ used another methodological source. There is currently little evidence to report safe studies on integumentary preparations using BISA. However, available studies on the antiphlogistic actions of BISA prove its anti-inflammatory, analgesic, and antioxidant efficacy. Therefore, the
\end{abstract}


authors consider that the sesquiterpene has clinical potential to be used in inflammatory processes of different etiologies, but further investigations are needed.

Keywords: Essential oils; BISA; Inflammation; Phytochemicals.

\section{Resumen}

El presente trabajo tuvo como objetivo identificar y sistematizar trabajos científicos que atribuyan al alfa-bisabolol (BISA) actividades antiflogísticas. Se trata de una revisión de la literatura, cuya selección de artículos se realizó en las bases de datos PubMed, Web of Science y Science Direct. Para fines de recolección de datos, se utilizaron las pautas PRISMA y el método de Bardin. La estrategia de búsqueda identificó 257 artículos que luego de la selección fueron elegibles para la revisión 37. Los criterios de inclusión definidos fueron: artículos originales, artículos de revisión, investigación experimental, ensayos clínicos, in vitro, in vivo y in silico, estudios de metaanálisis, en inglés, español y Lengua portuguesa. Solo se utilizaron trabajos con textos completos, accesibles y en el cronograma del estudio (enero de 2008 a julio de 2021). Se excluyó la literatura duplicada, pagada y no relacionada con el objetivo de la investigación. En cuanto al abordaje con temáticas específicas, tenemos que: $22(59,45 \%)$ artículos hacen referencia a los efectos antiinflamatorios, antioxidantes y analgésicos de BISA, 1 (2,70 \%) publicación de revisión y 14 (37,83\%) investigan las acciones del sesquiterpeno sobre el tejido tegumentario. Del total de estudios seleccionados, el 89,18\% $(n=33)$ se realizaron en un entorno de laboratorio y solo el 10,82\% $(n=4)$ utilizó otra fuente metodológica. Actualmente hay poca evidencia para informar estudios seguros sobre preparaciones tegumentarias utilizando BISA. Sin embargo, los estudios disponibles sobre las acciones antiflogísticas de BISA demuestran su eficacia antiinflamatoria, analgésica y antioxidante. Por tanto, los autores consideran que el sesquiterno tiene potencial clínico para ser utilizado en procesos inflamatorios de diferentes etiologías.

Palabras clave: Aceites esenciales; BISA; Inflamación; Fitoquímicos.

\section{Introdução}

O processo inflamatório é um mecanismo complexo de defesa, inerente aos seres vivos, e é requerido em situações que ocorra estímulos agressivos, de qualquer natureza. A resposta inflamatória (RI) desencadeia eventos celulares e moleculares no local da injúria, que iniciam a migração de células do sistema imune que terão como função, defender o organismo vivo da agressão sofrida (Kumar, Abbas \& Fausto, 2016).

A RI é representada por uma fase aguda, que se inicia imediatamente após uma lesão e pode ser resolutiva. Entretanto, se os mecanismos de defesa não forem efetivos, o processo inflamatório persiste e inicia-se a fase de respostas inflamatórias crônicas (Abdulkhaleq, Assi, Abdullah, Zamri-Saad, Taufiq-Yap \& Hezmee, 2018).

A persistência de um estímulo lesivo, promove respostas exacerbadas dos mecanismos de defesa, os quais promovem danos subjacentes aos tecidos e geram disfunção tecidual, por fibrose. Outro ponto a ser considerado, é que a inflamação local, pode assumir características da fase crônica da RI que são típicas, consideradas especializadas frente a um estímulo tecidual estressor persistente. Frequentemente, esse tipo de resposta tem como consequência a amplificação da RI, que posteriormente, envolverá todo o organismo, gerando efeito sistêmico (Medzhitov, 2010).

Medzhitov (2010) refere em seus estudos, que a presença de proteínas de choque térmico (heat shock), situações de hipóxia, presença de espécies reativas de oxigênio (ROS), baixa oferta de glicose e aminoácidos, nos tecidos inflamados, são fatores que acionam importantes mediadores pró-inflamatórios, tais como o: HSF-1, HIF-1 $\alpha$, NRF-2, AMPK e ATF-4. A persistência da ativação desses mediadores, acionam vias celulares de fatores de transcrição, que podem induzir o desenvolvimento de doenças auto-imunes. Sendo assim, vários estudos demonstram que a inflamação crônica está relacionada a perda de homeostase tecidual e ao desenvolvimento de uma variedade de doenças, entre elas: artrite reumatóide, asma brônquica, doenças autoimunes, doenças intestinais, neoplasias, entre outras (Medzhitov, 2008; Silva \& Dias, 2013; Cambui \& Natali, 2015; Singh, Baby, Rajguru, Patil, Thakkannavar \& Pujari, 2019; Figueiredo, 2019; Kirsch-Volders, Bolognesi, Ceppi, Bruzzone \& Fenech, 2020).

Estudos recentes, vem demonstrando que a hipóxia tecidual, adicionada à inflamação, é capaz de acelerar a taxa de metabolismo celular e o consumo de glicose, com consequente aumento da produção de ácido láctico, succinato e ácido itacônico, nos tecidos. Esses produtos estimulam monócitos e macrofágos a produzirem IL-1 $\beta$, IL-6, IL-17, IL-23 e inibem a 
motilidade de células T. Estados hipermetabólicos acarretam em consumo aumentado de oxigênio celular, que por sua vez colabora para o desenvolvimento de um ambiente com mais hipóxia e produção de compostos reativos. O resultado final, é o desequilíbrio entre os mecanismos homeostásicos de atividade antioxidante e a produção de espécies reativas de oxigênio (ROS) e nitrogênio (RNS) (Hussien, Abdalkadim, Mahbuba, Hadi, Jamil \& Al-Aubaidy, 2016; Lampropoulou, Sergushichev, Bambouskova, Nair, Vincent, Loginicheva, Cervantes-Barragan, Ma, Huang,, Griss, Weinheimer, Khader, Randolph, Pearce, Jones, Diwan, Diamond \& Artyomov, 2016; McGarry, Biniecka, Veale \& Fearon, 2018).

É sabido que as ROS e RNS são promotoras de oxidação de moléculas celulares cruciais, entre elas estão incluídas o DNA, lipídios e proteínas. Danos oxidativos no DNA resultam em mutagenicidade e formação de pró-mutagênicos, envolvidos nas transformações pré-neoplásicas e neoplásicas. Ademais, acionam mecanismos de peroxidação lipídica e danos proteicos severos que, em conjunto, inviabilizam a sobrevivência celular e colaboram para amplificação e perpetuação da RI, bem como, morte celular por necrose e/ou apoptose (Biniecka, Kennedy, Fearon, Ng, Veale \& O'Sullivanl, 2010; Hussain, Tan, Yin, Blachier, Tossou \& Rahu., 2016; Xiao, Zhong,, Xia, Tao \& Yin, 2017). Analisando os dados, pode-se concluir que tecidos inflamados proporcionam ambiente favorável para mais inflamação e mais danos celulares, uma vez que há uma confluência de fatores e mediadores que perpetuam um ciclo vicioso de retroalimentação inflamatória.

Os terpenóides são compostos naturais de maior representatividade na flora brasileira e mundial. Tem valor biológico inestimável por suas inúmeras atividades biológicas. A base de sua estrutura é o isopreno, o qual apresenta papel importante no metabolismo celular de organismos vivos (Tholl, 2015). A produção de terpenos pelas plantas é resultado de marcante estresse herbívoro, imposto por agressões de animais. Tal imposição, acabou resultando em similaridade estrutural e semelhança entre domínios de proteínas vegetais e animais. Essa característica é capaz de justificar a grande diversidade biológica desses compostos, bem como, seu valor na indústria farmacêutica e na medicina (Lorena \& Bicas, 2017; Bergman, Davis \& Phillips, 2019).

Entre as qualidades terapêuticas mais citadas dos terpenóides estão: a nutricional, a nutracêutica, antioxidativa, cardiotônica, microbicida, analgésica, antiinflamatória e antineoplásica (Tholl, 2015).

Os sesquiterpenos são um tipo de terpeno que apresentam alta volatilidade e conferem aroma e sabor peculiares às plantas que o sintetizam. As plantas mais populares que produzem sesquiterpenóides incluem o gengibre, cravo, alecrim, patchouli, sândalo e a camomila (Sharifi-Rad, Nazaruk, Polito, Morais-Braga, Rocha, Coutinho, Salehi, Tabanelli, Montanari, Del Mar Contreras, Yousaf, Setzer, Verma, Martorell, Sureda \& Sharifi-Rad, 2017). Atualmente o interesse farmacêutico por esses compostos vem aumentando significativamente em todo o mundo. A literatura relata que até o ano de 2018, foram identificados 161 tipos diferentes de sesquiterpenos monocíclicos, entre eles um vem se destacando por sua extensa bioatividade, o alfa-bisabolol (BISA) ou levomenol (Russell \& Jacob, 2010; Fu, Li, Li, Li, Chen \& Kang, 2019; Hu, Ma, Guo, Wen, Yan, Yang, Fu \& Liu, 2020).

O alfa - bisabolol é o principal óleo essencial extraído da camomila alemã (Matricaria camomila), porém há relatos na literatura que identificam outras fontes naturais, que apresentam na sua composição essencial o monoterpenóide, entre elas estão a: Eremanthus erythropappus, Salvia runcinata, Myoporum grassifolium, Smyrniopsis aucheri e Vanillosmopsis. (Kamatou \& Viljoen, 2009).

A camomila alemã é uma erva tradicionalmente utilizada na medicina da Europa Ocidental, Ásia ocidental, Índia, Alemanha e Estados Unidos (Pacífico, Araújo, Sousa, Costa, Souza, Pereira Júnior \& Medeiros, 2018). O óleo essencial BISA, compõe cerca de 50 - 90\% dos componentes das plantas supracitadas e foi isolado em 1951, por Isaac e colaboradores (Kamatou et al., 2008; Kamatou \& Viljoen, 2009). É um álcool sesquiterpeno monocíclico (Figura 1) e sua estrutura é semelhante as lactonas sesquiterpênicas, o que lhe confere grande biodiversidade (Russel \& Jacob, 2010). 
Figura 1. Estrutura química do alfa - bisabolol.

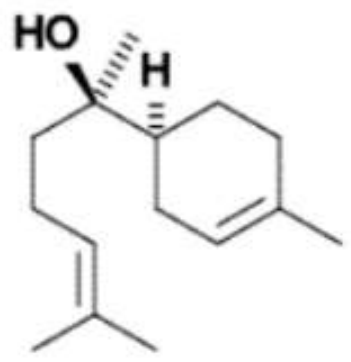

Fonte: Marco; Santos; Feitosa; Feitosa e Costa (2015).

O alfa-bisabolol pode se apresentar, em 4 possíveis conformações estruturais (Figura 2), os isômeros: (-)- $\alpha$-Bisabolol, (-)-epi- $\alpha$-Bisabolol, (+)- $\alpha$-Bisabolol e (+)-epi- $\alpha$-Bisabolol. Todos com propriedades biológicas importantes (Kamatou \& Viljoen, 2009).

Figura 2. Estrutura química dos estereoisômeros do alfa-bisabolol.

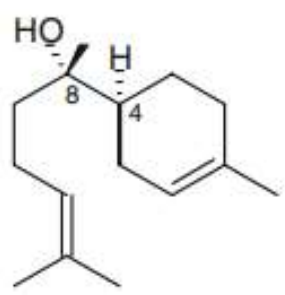

$(-)-\alpha$-Bisabolol

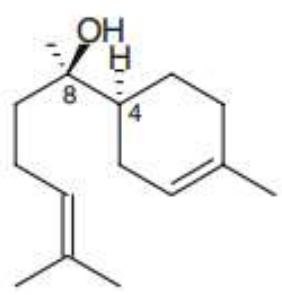

(-)-epi- $\alpha$-Bisabolol

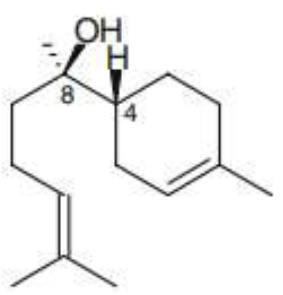

(+)- $\alpha$-Bisabolol

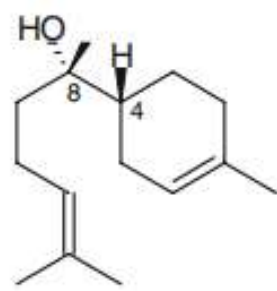

(+)-epi- $\alpha$-Bisabolol

Fonte: Kamatou e Viljoen (2009).

Estudos sobre as atividades farmacológicas dos componentes da camomila e do alfa-bisabolol, mostram que o terpenóide apresenta notáveis ações anti-inflamatória, antioxidante, antiparasitária, antineoplásica, neuroprotetora, antibacteriana, ansiolítica, hepatoprotetora, antinociceptiva e outras (Kim , Jung, Kim , Park, Lee \& Park, 2011; Rocha, 2011; Dela Ré \& Jorge, 2012; Solovăstru, Stîncanu , De Ascentii , Capparé , Mattana \& Vâţă, 2015; Miraj \& Alesaeidi, 2016)

Devido a sua extensa versatilidade biológica e os benefícios terapêuticos do BISA, bem como, de sua vasta utilização em diversas áreas da indústria farmacêutica e cosmecêutica (Sharifi-Rad, Nazaruk, Polito, Morais-Braga, Rocha, Coutinho, Salehi , Tabanelli , Montanari, Del Mar Contreras, Yousaf, Setzer, Verma , Martorell , Sureda \& Sharifi-Rad, 2018), esta revisão pretende apresentar um levantamento amplificado, utilizando a literatura científica mundial, das propriedades farmacológicas do alfa-bisabolol. Além disso, busca estimular novas pesquisas com esses compostos e procura difundir seu potencial clínico.

\section{Metodologia}

O estudo qualifica-se como revisão integrativa da literatura (Souza, Silva \& Carvalho, 2010) com enfoque em uma análise qualitativa, provendo a síntese de conhecimentos da literatura de abordagem teórica e empírica sobre o assunto. A pesquisa utilizou as bases de dados como: PubMed, Science Direct e Web of Science. Os termos de pesquisa empregados como descritores, combinados ou não com os operadores booleanos foram: alfa-bisabolol, levomenol, sesquiterpenos monocíclicos, propriedades farmacológicas, propriedades terapêuticas e bioatividade. Para o cruzamento de dados os 
denominadores booleanos AND e OR foram utilizados. Foram elegíveis para a pesquisa artigos originais, artigos de revisão, pesquisa experimental, ensaios clínicos, in vitro, in vivo e in silico, estudos de meta-análise, na língua inglesa, espanhola e portuguesa. Somente os trabalhos com textos completos, acessíveis e na linha do tempo do estudo (janeiro de 2008 a julho de 2021), foram utilizados.

Os estudos sobre a planta que discutiam sobre biossíntese, estruturas químicas, caracterização, identificação e que não estavam na linha de tempo estabelecida pelo estudo, foram excluídos. As literaturas pagas e duplicadas foram exclusas da análise. Os autores utilizaram para avaliar a qualidade do material pesquisado, o escore PRISMA como fluxograma de organização e elemento de verificação. A análise dos artigos selecionados foi baseada no método de Bardin (2011), o qual é dividido em 3 etapas. As etapas ocorrem de forma sequencial, que se baseiam na, interpretação, sistematização e categorização dos artigos elegidos para o estudo.

\section{Resultados e Discussão}

A busca ativa de artigos nas bases de dados, resultou em total de 257 estudos, sendo 168 publicados na PubMed, 38 na Science Direct e 51 na Web of Science. Todos os artigos estavam publicados no idioma inglês. Inicialmente, foram excluídos do estudo, 32 artigos por duplicidade. Durante a análise dos 225 trabalhos restantes, 149 não se relacionavam com o objetivo da pesquisa e 39 se baseavam em artigos sem acesso ao texto na íntegra. Após sistematização dos artigos, foram elegíveis para a revisão literária 37 artigos, sendo que $51.35 \%$ (n=19) foi encontrado na base de dados PubMed, $18.92 \%(\mathrm{n}=7$ ) na Science Direct e 29,72 \% (n=11) na Web of Science. Todos esses dados podem ser observados na Figura 3. 
Figura 3. Fluxograma das diferentes fases de seleção e elegibilidade dos artigos para revisão. Fonte: Page, McKenzie, Bossuyt,, Boutron, Hoffmann e Mulrow (2021).

\section{Identificação dos estudos via base de dados}
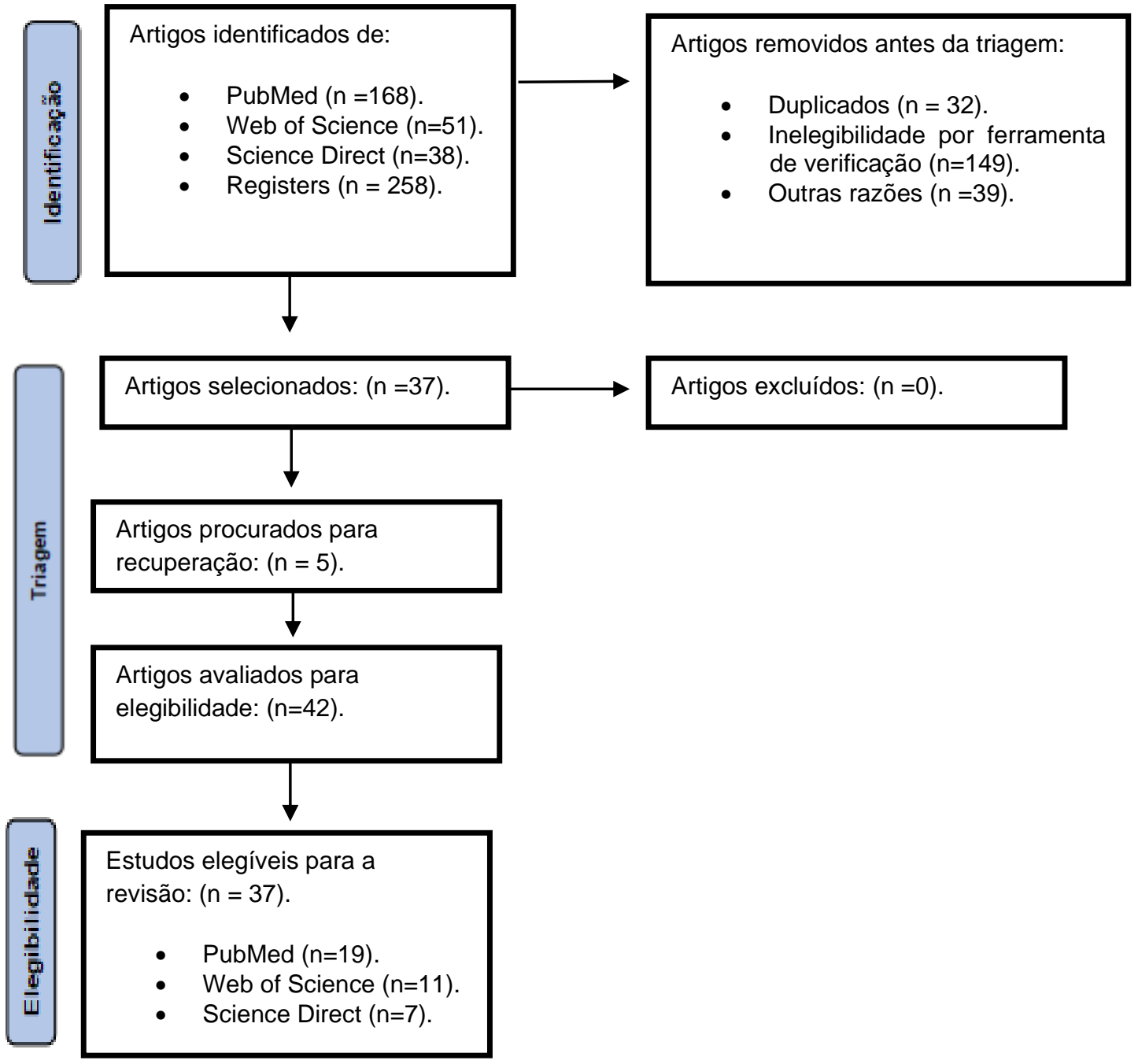

Fonte: Autores.(2021).

Em relação a abordagem de assuntos com temáticas específicas temos que: 22 (59.45 \%) são publicações que se referem aos efeitos antiinflamatório, antioxidante e analgésico do BISA, 1 (2.70\%) publicação de revisão sobre as atividades farmacológicas supracitadas e 14 (37.83 \%) investigam as ações antiflogísticas do sesquiterpeno sobre o tecido tegumentar.

Baseando na análise dos tipos de abordagens metodológicas encontradas nos trabalhos, foram produzidos em laboratório 33 artigos (89.18\%), sendo que desses, 7 (18.91\%) utilizaram estudos in vivo em voluntários humanos, 14 $(37.83 \%)$ utilizaram estudos in vivo em animais, 6 (16.21\%) foram realizados estudos com animais in vivo, 4 (10.81 \%) utilizaram estudos em animais in vitro e in vitro concomitantemente, $2.70 \%(\mathrm{n}=1)$ se basearam em estudos in vivo e in vitro utilizando humanos e por fim, $1(2.70 \%)$ pesquisa utilizou animais e testes in vivo, in vitro e in silico. Foram realizados 8 estudos (21.62\%) em humanos, $25(67.56 \%)$ pesquisas em animais e os demais (10.82 \%) são revisões de bibliografia.

Os autores do trabalho acharam, mais didático e funcional separar em quadros os dados coletados por propriedade farmacológica pesquisada, facilitando ao leitor a busca por temática específica. Além disso, os artigos estão elencados por 
ordem cronológica, do período mais antigo ao mais recente. Todos os quadros foram produzidos com as informações que identificam os trabalhos elegíveis para a revisão, tais como: a citação dos autores, data de publicação, título do artigo, base de dados, metodologia, objetivo do estudo e suas respectivas conclusões.

No Quadro 1, são apresentados os estudos selecionados que investigaram a atividade farmacológica do BISA sobre o tecido tegumentar.

Quadro1. Referências bibliográficas sobre as ações biológicas do alfa-bisabolol sobre a pele.

\begin{tabular}{|c|c|c|c|c|c|}
\hline $\mathbf{N}^{\mathbf{0}}$ & Título/Ano/Autor & $\begin{array}{l}\begin{array}{l}\text { Base de } \\
\text { dados }\end{array} \\
\end{array}$ & Metodologia & Objetivo de estudo & Conclusões \\
\hline 1 & $\begin{array}{l}\text { Bisabolol } \\
\text { Russell e Jacob } \\
(2010) \text {. }\end{array}$ & $\begin{array}{l}\text { Science } \\
\text { Direct }\end{array}$ & $\begin{array}{l}\text { Revisão bibliográfica. } \\
\text { Pesquisa do potencial } \\
\text { alergênico do BISA. } \\
\text { Elenca os produtos } \\
\text { cosméticos } \\
\text { disponíveis } \\
\text { mercado } \\
\text { bisabolol. }\end{array}$ & $\begin{array}{l}\text { Levantar relatos de } \\
\text { casos de dermatites } \\
\text { relacionadas ao uso } \\
\text { de preparações } \\
\text { cosméticas com } \\
\text { BISA. }\end{array}$ & $\begin{array}{l}\text { Alertar a comunidade médica } \\
\text { da necessidade de orientação } \\
\text { aos pacientes que utilizam } \\
\text { bisabolol em formulações } \\
\text { cosmêceuticas. do potencial } \\
\text { alergênico e da concentração } \\
\text { recomendada de BISA na } \\
\text { aplicação sobre a pele. }\end{array}$ \\
\hline 2 & $\begin{array}{l}\text { Whitening effect of } \\
\text { a-bisabolol in Asian } \\
\text { women subjects } \\
\text { Lee, Jun, Jung, Ha e } \\
\text { Park } \\
\text { (2010). }\end{array}$ & PubMed & $\begin{array}{l}\text { Pesquisa experimental } \\
\text { in vivo. Um ensaio } \\
\text { duplo-cego, } \\
\text { controlado por } \\
\text { veículo, randomizado } \\
\text { em mulheres com } \\
\text { hiperpigmentação. }\end{array}$ & $\begin{array}{l}\text { Avaliar os efeitos } \\
\text { clínicos de o uso de } \\
\text { creme contendo } \\
0,5 \% \text { de bisabolol } \\
\text { em pele pigmentada } \\
\text { por um período de } 2 \\
\text { meses. }\end{array}$ & $\begin{array}{l}\text { Após } 8 \text { semanas } \\
\text { tratamento com o creme } \\
\text { contendo bisabolol, foi } \\
\text { observado significativo efeito } \\
\text { de clareamento na pele } \\
\text { hiperpigmentada para a } \\
\text { maioria das voluntárias que } \\
\text { testou o creme. }\end{array}$ \\
\hline 3 & $\begin{array}{l}\text { Compositae- } \\
\text { associated allergic } \\
\text { contact dermatitis } \\
\text { from bisabolol } \\
\text { Jacob, Matiz e } \\
\text { Herro (2011). }\end{array}$ & PubMed & $\begin{array}{l}\text { Estudo retrospectivo, } \\
\text { descritivo e analítico. } \\
\text { Relação do uso de } \\
\text { hidratante contendo } \\
\text { bisabolol } \\
\text { surgimento } \\
\text { dermatite alérgica de } \\
\text { contato (DAC). }\end{array}$ & 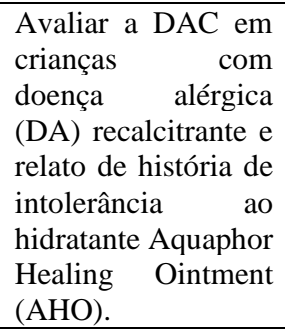 & $\begin{array}{l}\text { O bisabolol, um álcool } \\
\text { sesquiterpênico, deve ser } \\
\text { considerado uma causa } \\
\text { potencial de DAC em } \\
\text { crianças com DA e com } \\
\text { histórico de intolerância a } \\
\text { hidratantes. }\end{array}$ \\
\hline 4 & $\begin{array}{l}\text { Antioxidant activity } \\
\text { of Matricaria } \\
\text { chamomilla L. } \\
\text { extract and clinical } \\
\text { efficacy of } \\
\text { cosmetic } \\
\text { formulations } \\
\text { containing this } \\
\text { extract and its } \\
\text { isolated compounds } \\
\text { Nóbrega, } \\
\text { Wagemakere } \\
\text { Maia Campos } \\
\text { (2013). }\end{array}$ & PubMed & $\begin{array}{l}\text { Estudo experimental } \\
\text { in vitro e in vivo. Foi } \\
\text { avaliado a atividade } \\
\text { antioxidanter por } \\
\text { ensaio de } \\
\text { quimiofluorescência } \\
\text { do extrato de } \\
\text { camomila e apigenina, } \\
\text { em diferentes } \\
\text { concentrações. Após, } \\
\text { foram feitas } \\
\text { formulações de } \\
\text { emulsões com BISA, } \\
\text { camomila e apigenina. } \\
\text { Os voluntários } \\
\text { utilizaram as } \\
\text { formulações em uma } \\
\text { única aplicação e } \\
\text { outro grupo por } 4 \\
\text { semanas. } \\
\text { características da pele } \\
\text { foram avaliadas. }\end{array}$ & $\begin{array}{lr}\text { Avaliar o potencial } \\
\text { antioxidante } \\
\text { extrato do } \\
\text { camomila, de } \\
\text { como a em } \\
\text { clínica } & \text { na } \\
\text { hidrataçácia } \\
\text { e das propriedades } \\
\text { mecânicas da pele. }\end{array}$ & $\begin{array}{l}\text { O extrato de camomila, foi } \\
\text { eficaz na neutralização de } \\
\text { radicais livres e na melhora } \\
\text { das propriedades mecânica e } \\
\text { hidratante da pele, } \\
\text { portanto, apresenta potencial } \\
\text { em formulações cosméticas } \\
\text { com este propósito. }\end{array}$ \\
\hline 5 & $\begin{array}{lr}\alpha-(-) \text {-bisabolol } & \\
\text { Reduces } & \text { Pro- } \\
\text { inflammatory } & \\
\text { Cytokine } & \\
\text { Production } & \text { and } \\
\text { Ameliorates } & \text { Skin } \\
\text { Inflammation. } & \\
\end{array}$ & $\begin{array}{l}\text { Web of } \\
\text { Science }\end{array}$ & $\begin{array}{l}\text { Pesquisa experimental } \\
\text { in vivo, in vitro e in } \\
\text { silico. O estudo in } \\
\text { vivo } \\
\text { camundongo } r \text { utilizou } \\
\text { edema } \\
\begin{array}{l}\text { com } \\
\text { orelha.Foram }\end{array}\end{array}$ & $\begin{array}{l}\text { Avaliar o seu perfil } \\
\text { terapêutico contra a } \\
\text { inflamação da pele } \\
\text { por meio de ensaios } \\
\text { in vitro, in vivo e in } \\
\text { silico. }\end{array}$ & $\begin{array}{l}\text { Os autores sugerem que o } \alpha- \\
(-) \text { - bisabolol pode ser um } \\
\text { candidato terapêutico útil para } \\
\text { o tratamento da inflamação da } \\
\text { pele. }\end{array}$ \\
\hline
\end{tabular}




\begin{tabular}{|c|c|c|c|c|c|}
\hline & $\begin{array}{lr}\text { Maurya, } & \text { Singh, } \\
\text { Dubey, Srivastava, } \\
\text { Luqman e } \\
\text { Bawankule (2014). }\end{array}$ & & $\begin{array}{l}\text { analisados a atividade } \\
\text { anti-inflamatória e a } \\
\text { produção de citocinas } \\
\text { pró-inflamatórias. }\end{array}$ & & \\
\hline 6 & $\begin{array}{l}\text { Anti-Aging } \\
\text { Potential of } \\
\text { Phytoextract } \\
\text { Loaded- } \\
\text { Pharmaceutical } \\
\text { Creams for Human } \\
\text { Skin Cell } \\
\text { Longetivity } \\
\text { Jadoon, Karim, Bin } \\
\text { Asad, Akram, } \\
\text { Khan, Malik, Chen } \\
\text { e Murtaza } \\
\text { (2015). }\end{array}$ & $\begin{array}{l}\text { Science } \\
\text { Direct }\end{array}$ & $\begin{array}{l}\text { Revisão bibliográfica. } \\
\text { Revisão em base de } \\
\text { dados de estudos in } \\
\text { vivo com plantas. }\end{array}$ & $\begin{array}{l}\text { Avaliar o efeito } \\
\text { protetor } \\
\text { antioxidante de } \\
\text { fitoformulações na } \\
\text { pele exposta a raios } \\
\text { UVR } \\
\text { envelhecimento. } \\
\text { Entre os compostos, } \\
\text { estão os terpenos. }\end{array}$ & $\begin{array}{l}\text { Os compostos } \\
\text { estudados sugerem ter boa } \\
\text { atividade protetora sobre os } \\
\text { raios UVR e envelhecimento } \\
\text { da pele. }\end{array}$ \\
\hline 7 & $\begin{array}{l}\text { Formulation } \\
\text { Containing } \\
\text { Ozonated Oil and a- } \\
\text { Bisabolol } \\
\text { in the Topical } \\
\text { Treatment } \\
\text { Chronic of } \\
\text { Leg Ulcers } \\
\text { Solovăstru, } \\
\text { Stîncanu, } \\
\text { Ascentii, Capparé, } \\
\text { Mattana, e Vâţă. } \\
\text { (2015). }\end{array}$ & $\begin{array}{l}\text { Science } \\
\text { Direct }\end{array}$ & $\begin{array}{l}\text { Pesquisa } \\
\text { experimental. Estudo } \\
\text { randomizado, com } \\
\text { duração de } 30 \text { dias e } \\
\text { avaliou a evolução de } \\
\text { cicatrização de feridas } \\
\text { crônicas com duas } \\
\text { formulações. }\end{array}$ & $\begin{array}{l}\text { Avaliar o efeito } \\
\text { cicatrizante } \\
\text { BISA em feridas } \\
\text { crônicas de origem } \\
\text { venosa na perna. }\end{array}$ & $\begin{array}{l}\text { A formulação de spray com } \\
\text { bisabolol } \\
\text { promissora comostrou-se } \\
\text { importante } \\
\text { opção terapêutica } \\
\text { tratamento adjuvante no } \\
\text { úlceras venosas. }\end{array}$ \\
\hline 8 & $\begin{array}{l}\text { Highly efficient and } \\
\text { compatible } \\
\text { shampoo for use } \\
\text { after hair transplant. } \\
\text { Schweiger, } \\
\text { Schoelermann, } \\
\text { Filbry } \\
\text { Hamann, Moser e } \\
\text { Rippke. } \\
(2015) \text {. }\end{array}$ & $\begin{array}{l}\text { Science } \\
\text { Direct }\end{array}$ & $\begin{array}{l}\text { Pesquisa quase } \\
\text { experimental. } \\
\text { Voluntários utilizaram } \\
\text { um shampoo } \\
\text { contendo BISA, após } \\
\text { transplante capilar. } \\
\text { Foram avaliados por } \\
\text { cirurgiões plásticos e } \\
\text { autoavaliação. }\end{array}$ & $\begin{array}{l}\text { Analisar a área de } \\
\text { transplante com o } \\
\text { uso do shampoo de } \\
\text { BISA. no que se } \\
\text { refere às suas } \\
\text { propriedades } \\
\text { antiirritante } \\
\text { antiinflamatória, e } \\
\text { bem como a } \\
\text { compatibilidade } \\
\text { com a pele. }\end{array}$ & $\begin{array}{l}\text { A formulação com BISA } \\
\text { exerceu excelente resultado } \\
\text { sobre a recuperação dos } \\
\text { voluntários que realizaram o } \\
\text { transplante capilar, sendo } \\
\text { recomendado o uso pós- } \\
\text { cirurgia. }\end{array}$ \\
\hline 9 & $\begin{array}{l}\text { A Multi-Target } \\
\text { Approach toward } \\
\text { the Development of } \\
\text { Novel Candidates } \\
\text { for } \\
\text { Antidermatophytic } \\
\text { Activity: } \\
\text { Ultrastructural } \\
\text { Evidence on } \\
\alpha \text {-Bisabolol- } \\
\text { Treated Microsporu } \\
\text { m gypseum } \\
\text { Romagnoli, } \\
\text { Baldisserotto, } \\
\text { Malisardi, } \\
\text { Vicentini,Mares, } \\
\text { Andreotti, Vertuani } \\
\text { e Manfredini } \\
\text { (2015). }\end{array}$ & PubMed & $\begin{array}{l}\text { Estudo experimental } \\
\text { in vitro. } \\
\text { Análise in vitro da } \\
\text { ação antifúngica de } \\
\text { diferentes compostos } \\
\text { e fungos. }\end{array}$ & $\begin{array}{l}\text { Avaliar a inibição } \\
\text { da germinação de } \\
\text { esporos e alterações } \\
\text { morfológicas de } 9 \\
\text { compostos naturais } \\
\text { em laboratório em } \\
\text { culturas de fungos. }\end{array}$ & 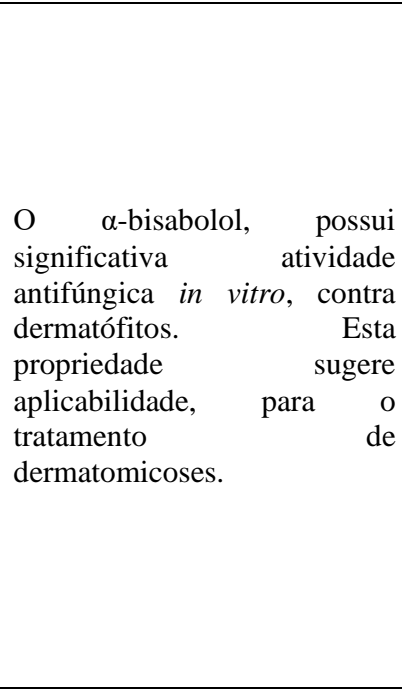 \\
\hline 10 & $\begin{array}{l}\text { Research on the } \\
\text { immunosuppressive } \\
\text { activity of } \\
\text { ingredients } \\
\text { contained in } \\
\text { sunscreens. } \\
\text { Frikeche, Couteau, } \\
\text { Roussakis }\end{array}$ & PubMed & $\begin{array}{l}\text { Pesquisa experimental } \\
\text { in vitro. } \\
\text { Análise de citometria } \\
\text { de fluxo da ação } \\
\text { imunossupressora de } \\
\text { filtros solares } \\
\text { contendo alantoína, }\end{array}$ & $\begin{array}{l}\text { Avaliar a ação da } \\
\text { alantóina, bisabolol } \\
\text { e enoxolol sobre as } \\
\text { células da resposta } \\
\text { imunossupressora: } \\
\text { células dendríticas } \\
\text { (DC), células T e } \\
\text { das células que }\end{array}$ & $\begin{array}{l}\text { Os resultados demonstram } \\
\text { que as moléculas testadas têm } \\
\text { efeitos inibitórios sobre as } \\
\text { DCs, células T e células de } \\
\text { queratinócitos. } \\
\text { ingrediente deve ser usado } \\
\text { com cuidado em doses } \\
\text { reduzidas ou mesmo }\end{array}$ \\
\hline
\end{tabular}




\begin{tabular}{|c|c|c|c|c|c|}
\hline & $\begin{array}{l}\text { Coiffard } \\
\text { (2015). }\end{array}$ & & enoxolol e bisabolol. & $\begin{array}{l}\text { participam da } \\
\text { proliferação celular. }\end{array}$ & $\begin{array}{l}\text { removido de algumas } \\
\text { preparações cosméticas, como } \\
\text { protetores solares. }\end{array}$ \\
\hline 11 & $\begin{array}{l}\text { Preparation of } \\
\text { Alpha-Bisabolol } \\
\text { and Phenylethyl } \\
\text { Resorcinol/Tio } \\
2 \text { Hybrid } \\
\text { Composites for } \\
\text { Potential } \\
\text { Applications in } \\
\text { Cosmetics. } \\
\text { Leong, Jang, Hyun, } \\
\text { Jung, Hong, Jeong e } \\
\text { Oh (2016). }\end{array}$ & $\begin{array}{l}\text { Web of } \\
\text { Science }\end{array}$ & $\begin{array}{l}\text { Pesquisa experimental } \\
\text { in vitro. } \\
\text { Desenvolvimento de } \\
\text { uma microesfera de } \\
\text { titânio acrescida de } \\
\text { alfa-bisabolol e } \\
\text { resorcinol. Análise da } \\
\text { atividade antioxidante } \\
\text { de ambas por meio de } \\
\text { ensaio colorimétrico. }\end{array}$ & $\begin{array}{lr}\text { Produzir Híbridos } \\
\text { bifuncionais } \\
\text { contendo } & \text { alfa- } \\
\text { bisabolol resorcinol } \\
/ \text { TiO2 para } \\
\text { aplicação na área } \\
\text { cosmética, para } \\
\text { tratamento anti- } \\
\text { envelhecimento } \\
\text { e } & \text { de } \\
\text { hiperpigmentação. }\end{array}$ & $\begin{array}{l}\text { A estratégia pode ser eficaz } \\
\text { para produzir filtros UV } \\
\text { inorgânico e híbridos } \\
\text { multifunções e vantagens que } \\
\text { poderiam ter } \\
\text { grande demanda nas } \\
\text { aplicações cosméticas. } \\
\text { O estudo comprova a } \\
\text { atividade antioxidante do } \\
\text { BISA. }\end{array}$ \\
\hline 12 & $\begin{array}{l}\text { A starch, } \\
\text { glycyrretinic, zinc } \\
\text { oxide and bisabolol } \\
\text { based cream in the } \\
\text { treatment of chronic } \\
\text { mild-to-moderate } \\
\text { atopic dermatitis in } \\
\text { children: a three- } \\
\text { center, assessor } \\
\text { blinded trial. } \\
\text { Licari, } \\
\text { Ruffinazzi, } \\
\text { Filippo, Castagnoli, } \\
\text { Marseglia, } \\
\text { Agostinis, Puviani, } \\
\text { Milani e Marsegli } \\
\text { (2017). }\end{array}$ & PubMed & $\begin{array}{l}\text { Pesquisa experimental } \\
\text { in vivo. Estudo duplo } \\
\text { cego, multicêntrico } \\
\text { com crianças com } \\
\text { diagnóstico re de } \\
\text { dermatite atópica } \\
\text { (DA) leve a } \\
\text { moderada.Foi } \\
\text { analisado a evolução } \\
\text { do quadro de eczema } \\
\text { da DA, após o uso } 2 \mathrm{x} \\
\text { ao dia de creme } \\
\text { contendo bisabolol, } \\
\text { por um período de } 3 \text { e } \\
6 \text { semanas. }\end{array}$ & $\begin{array}{l}\text { Avaliar o potencial } \\
\text { antieczematoso de } \\
\text { preparações } \\
\text { contendo bisabolol } \\
\text { em crianças com } \\
\text { diagnóstico de } \\
\text { dermatite atópica } \\
\text { leve e moderada. }\end{array}$ & $\begin{array}{l}\text { Os autores apoiam a eficácia e } \\
\text { a tolerabilidade do creme sem } \\
\text { corticosteroide contendo } \\
\text { amido, } \\
\text { ácido glicirretínico e bisabolol } \\
\text { no tratamento de dermatite } \\
\text { atópica crônica leve a } \\
\text { moderada em crianças. }\end{array}$ \\
\hline 13 & $\begin{array}{l}\text { Determination of } \\
\text { the Influence of the } \\
\text { Antiphlogistic } \\
\text { Ingredients } \\
\text { Panthenol and } \\
\text { Bisabolol on the } \\
\text { SPF Value in vivo. } \\
\text { Werner, Herling, } \\
\text { Garbe, Theek, } \\
\text { Tronnier, Heinrich } \\
\text { e Braun. } \\
\text { (2017). }\end{array}$ & PubMed & $\begin{array}{l}\text { Pesquisa experimental } \\
\text { in vivo. Neste estudo } \\
\text { foram utilizados } \\
\text { voluntários } r \text { sadios } \\
\text { entre } 18-70 \text { ano e } \\
\text { modelo de eritema } \\
\text { provocado por } \\
\text { irradiação UV. As } \\
\text { formulações contendo } \\
\text { BISA }(0.1-0.2 \%) \text { e a } \\
\text { eficácia antiflogística } \\
\text { foi analisada. }\end{array}$ & $\begin{array}{l}\text { Investigar a } \\
\text { influência potencial } \\
\text { dos ingredientes } \\
\text { antiflogísticos } \\
\text { pantenol e bisabolol } \\
\text { em filtros solares no } \\
\text { valor de FPS } \\
\text { determinado in vivo. }\end{array}$ & $\begin{array}{l}\text { Os ingredientes antiflogísticos } \\
\text { pantenol e bisabolol } \\
\text { incorporados na fórmula do } \\
\text { protetor solar testada não } \\
\text { interferem na vermelhidão do } \\
\text { eritema e, portanto, não } \\
\text { afetam o valor do FPS in vivo. }\end{array}$ \\
\hline 14 & $\begin{array}{l}\text { When Testosterone } \\
\text { Needs to be } \\
\text { Contrasted: A } \\
\text { Preliminary Study } \\
\text { of Scar Prevention } \\
\text { in Transmen Top } \\
\text { Surgery with an } \\
\text { Innovative Galenic } \\
\text { Preparation. } \\
\text { Tanini, } \\
\text { Calabrese, Fisher } \\
\text { Maggi e Lo Russo } \\
\text { (2020). }\end{array}$ & $\begin{array}{l}\text { Science } \\
\text { Direct }\end{array}$ & $\begin{array}{l}\text { Estudo experimental } \\
\text { in vivo. } \\
\text { Um } \\
\text { prospectivo } \\
\text { randomizado } \\
\text { controlado, de } \\
\text { pacientes transgênico } \\
\text { submetidas a } \\
\text { mastectomia entre } \\
\text { fevereiro de } 2014 \text { e } \\
\text { junho de 2019.Foram } \\
\text { tratadas por } 12 \text { meses } \\
\text { com controle e com } \\
\text { gel de silicone e alfa } \\
\text { bisabolol. }\end{array}$ & $\begin{array}{l}\text { Criar } r \text { uma } \\
\text { preparação galênica } \\
\text { inovadora de ação } \\
\text { cicatrizante com os } \\
\text { compostos: alfa - } \\
\text { bisabolol, } \\
\text { espironolactona e } \\
\text { silicone. }\end{array}$ & 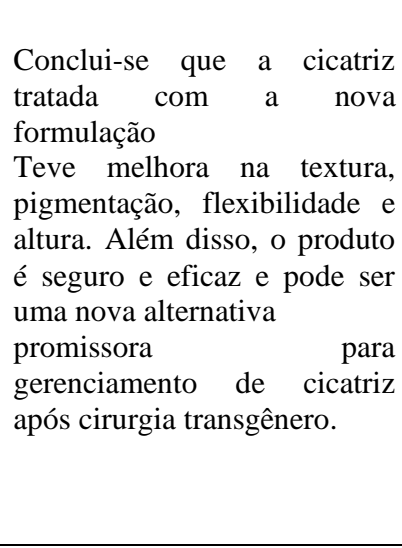 \\
\hline
\end{tabular}

Fonte: Autores (2021).

O incremento de pesquisa com o BISA, sobre suas propriedades no tecido tegumentar, datam de desde 2010. Lee et al (2010) faz uso do composto na forma de creme $0.5 \%$, por um período de 2 meses, em pele de mulheres com quadro de hiperpigmentação. Os resultados sugerem que o terpenóide reduz as discromias, e apresenta vantagens adicionais ao que se 
refere a custos de produção. Os estudos de Nóbrega et al. (2013), realizados in vitro (ensaios de atividade antioxidante) e in vivo, utilizando em voluntários, emulsão contendo $\alpha$ - bisabolol, por um período de 4 semanas, corroboram com os anteriores. Os resultados do ensaio in vivo, reafirmam a boa eficiência do alfa-bisabolol em incrementar o processo fisiológico cicatricial, bem como, ressalta a capacidade do composto em melhorar a hidratação e características mecânicas da pele, quesitos importantes para a resolução de feridas cutâneas.

Em contrapartida, Jacob e Hsu (2010) e Jacob et al. (2011), alertam a comunidade científica do potencial alergênico e desencadeador de dermatite atópica do BISA, em adultos e crianças. Em ambos os trabalhos, os autores relatam casos de pacientes que utilizavam um hidratante formulado com bisabolol e apresentaram crises de dermatite atópica. Entre 7 pacientes com diagnóstico de DA, seis foram atendidos em ambulatório com histórico de intolerância ao hidratante. Entretanto, os autores sugerem que os quadros de intolerância podem estar relacionados com as características intrínsecas do paciente ao composto e a outros hidratantes, uma vez que desses seis, pelo menos quatro tinham histórico de quadro alérgico por hidratantes. Mencionam também, que a alta concentração de BISA na formulação (5\%), pode ser a causa do potencial alergênico e recomenda que, para o preparo de formulações tópicas com o BISA, sejam utilizadas concentrações de 0.1 a $0.5 \%$, no máximo (Jacob \& Hsu, 2010). Desta forma, são necessárias maiores investigações a respeito da concentração mínima eficaz e toxicidade do BISA, para que possam garantir uma padronização da concentração do sesquiterpeno em formulações galênicas.

Tal afirmação torna-se pertinente, pois analisando o quadro 1, pode-se perceber que o maior número de trabalhos publicados acerca da ação do bioativo, sobre o sistema tegumentar, está concentrada no ano de 2015, perfazendo $41.66 \%$ do total das publicações. Sendo que apenas 2 artigos, do total, têm datas mais recentes de publicações, 2017 (8.33 \%) e 2020 $(8.33 \%)$. Ademais, há pouca produção de pesquisas que analisam os mecanismos envolvidos nas propriedades supracitadas.

Um estudo randomizado utilizando 29 pacientes acima de 18 anos e com diagnóstico de úlcera venosa crônica em membro inferior, foi capaz de demonstrar que, o uso diário de uma formulação combinada de óleo ozonizado e alfa-bisabolol, por 30 dias, reduziu progressiva e significativamente a área lesada, quando comparado com o tratamento padrão. As feridas foram avaliadas nos dias 7, 14 e 30 e o cálculo de área de superfície e velocidade de cicatrização diminuíram em $34 \%, 59 \%$ e $73 \%$, respectivamente. Sendo assim, a droga vegetal apresenta promissor valor terapêutico e pode ser utilizada como agente adjuvante em tratamento de feridas crônicas (Solovăstru et al., 2015). Adicionalmente, o uso de alfa-bisabolol em uma preparação em forma de shampoo, utilizada em pacientes pós transplante capilar, mostrou ser um ótimo adjuvante no pósoperatório, pois foi capaz de diminuir a inflamação e formação de crostas no local das incisões, resultando em um melhor desfecho clínico (Schweiger et al., 2015).

O uso de alfa-bisabolol para tratamento de hiperpigmentação cutânea, tem mostrado boa eficácia e vantagens adicionais aos recursos já empregados na clínica para a discromia. Os estudos mostram que além da boa eficácia em amenizar melasmas e efélides, há benefícios em relação ao custo e benefício de formulações dermatológicas com o BISA (Jadoon et al., 2015).

Segundo Frikeche et al. (2015) o uso de bisabolol em filtros solares não seria recomendado, uma vez que este provoca diminuição da capacidade proliferativa das células da pele, bem como é capaz de aumentar a liberação de TGF - $\beta 1$ pelos queratinócitos, resultando em um estado de imunossupressão no ambiente cutâneo. Os autores relatam que há prejuízo na maturação das DC e que a junção dos achados científicos, pode colaborar para o desenvolvimento de neoplasias da pele, nos indivíduos exposto aos raios UV e utilizarem esses filtros solares. Sendo assim, concluem que é necessário cautela no uso ou retirada dos produtos do comércio. Outras publicações relevantes sobre os efeitos do $\alpha$-bisabolol no tecido cutâneo, foram feitas por Romagnoli et al. (2015) e Leong et al. (2016). Os artigos salientam as características dermotofítica e antioxidante do 
composto estudado. Tais propriedades contribuem para seu uso em formulações que se destinam a tratar dermatomicoses, e em cosméticos antienvelhecimento, por sua ótima capacidade antioxidante.

Para Licari et al. (2017) o emprego de um creme formulado com bisabolol, foi extremamente benéfico para a redução de lesões eczematosas em crianças com dermatite atópica crônica leve a moderada. Os autores da pesquisa aplicaram topicamente, por 6 semanas, uma formulação contendo bisabolol e outros aditivos, em 30 crianças diagnosticadas com DA leve a moderada, com idade média de 5 anos. Ao longo do tratamento, as lesões eczematosas foram avaliadas e observou-se que $87 \%$ dos voluntários, apresentaram redução das lesões. Ademais, os pesquisadores enaltecem a eficácia e tolerabilidade da formulação tópica, uma vez que o creme pode substituir o uso de formulações com corticosteróides e assim, diminuir as complicações associadas ao seu uso. Por outro lado, Werner et al. (2017) revelam em seus estudos que o uso de preparações de BISA a $0.1-0.2 \%$, in vivo não alteram os sinais cardinais da inflamação e não interferem nos valores de FPS.

Outro estudo randomizado, conduzido entre setembro de 2018 a setembro de 2019, utilizando o alfa - bisabolol em uma formulação, foi desenvolvido para a análise da cicatrização de feridas pós-cirúrgicas. Foram selecionados 15 pacientes transgênicos que realizaram mastectomia total bilateral. $\mathrm{O}$ grupo tratado com um composto contendo espironolactona, alfa bisabolol e gel de silicone, por 12 meses, demonstrou eficácia estatística em longo prazo, tanto em relação a pigmentação, vascularização e flexibilidade do tecido cutâneo. O índice de satisfação também foi maior no grupo tratado (Tanini et al., 2020). No que diz respeito à avaliação do alfa-bisabolol nas enfermidades cutâneas de origem irritativa e alergênica, in vivo, há controvérsias. Durante o levantamento de dados e seleção dos artigos, os autores puderam observar um grande volume de publicações acerca das propriedades antinociceptiva e anti-inflamatória do alfa-bisabolol, as quais cresceram em ordem exponencial ao longo dos anos, com produções maiores nos anos de $2011(n=3)$ e 2019 (n=3) e 2020 (n=3), contabilizando $21.43 \%$ / ano. O total de estudos científicos encontrados com o tema específico foi de 14, dos 37 artigos selecionados para a revisão, correspondendo a 37,83\% das produções de pesquisa.

As publicações relacionadas ao uso de BISA, em estudos que investigam sua capacidade anti-inflamatória, antioxidativa e antinociceptiva, podem ser observadas no Quadro 2. 
Quadro 2. Distribuição das referências sobre a atividade antiinflamatória e antinociceptiva do $\alpha$-bisabolol incluídas na revisão.

\begin{tabular}{|c|c|c|c|c|c|}
\hline $\mathbf{N}^{\circ}$ & Título/Ano/Autor & $\begin{array}{c}\text { Base de } \\
\text { dados }\end{array}$ & Metodologia & Objetivo de estudo & Conclusões \\
\hline 1 & $\begin{array}{l}\text { Gastroprotection of } \\
(-) \text {-a-bisabolol on acute } \\
\text { gastric mucosal lesions in } \\
\text { mice: the possible involved } \\
\text { pharmacological } \\
\text { mechanisms. } \\
\text { Rocha, Venâncio, Moura, } \\
\text { Silva, Neto, Riosa, Sousa, } \\
\text { Vasconcelos, Fonteles e } \\
\text { Sousa } \\
(2010) \text {. }\end{array}$ & PubMed & $\begin{array}{l}\text { Pesquisa experimental } \\
\text { in vivo. O estudo } \\
\text { promoveu a indução } \\
\text { de lesões gástricas em } \\
\text { animais e foi } \\
\text { realizado tratamento } \\
\text { prévio, via oral, com } \\
\text { BISA (100 e } 200 \mathrm{mg} / \\
\text { Kg). Foram feitas } \\
\text { dosagens r de } \\
\text { glutationa reduzida no } \\
\text { estomago. }\end{array}$ & $\begin{array}{l}\text { Avaliar a função } \\
\text { gastroprotetora } \\
\text { ação de (-) }- \text { a- } \\
\text { bisabolol } \\
\text { modelos de úlcera } \\
\text { induzida por etanol } \\
\text { e indometacina em } \\
\text { camundongos, } \\
\text { e investigar os } \\
\text { mecanismos } \\
\text { farmacológicos } \\
\text { envolvidos nesta } \\
\text { ação. }\end{array}$ & $\begin{array}{l}\text { O efeito } \\
\text { gastroprotetor } \\
\text { promovido por } \\
(-) \text { - a-bisabolol } \\
\text { pode estar } \\
\text { associado a um } \\
\text { aumento de } \\
\text { biodisponibilidade } \\
\text { de grupos sulfidrila } \\
\text { gástricos levando a } \\
\text { uma redução da } \\
\text { lesão por oxidação } \\
\text { gástrica (atividade } \\
\text { antioxidante). }\end{array}$ \\
\hline 2 & $\begin{array}{l}(-)-\alpha-\text { Bisabolol-induced } \\
\text { gastroprotection is associated } \\
\text { with reduction in lipid } \\
\text { peroxidation, superoxide } \\
\text { dismutase activity and } \\
\text { neutrophil migration. } \\
\text { Rocha, Oliveira, Araújo, } \\
\text { Rios, Carvalho, Vasconcelos, } \\
\text { Macêdo, Soares, Sousa e } \\
\text { Sousa } \\
\text { (2011). }\end{array}$ & PubMed & $\begin{array}{l}\text { Estudo experimental } \\
\text { in vivo e in vitro. } \\
\text { Investigar a possível } \\
\text { ação antioxidante do } \\
\text { BISA na redução do } \\
\text { dano gástrico } \\
\text { induzido pelo etanol. } \\
\text { Realizou-se análise } \\
\text { histopatológica e } \\
\text { mensuração } \\
\text { compostos de } \\
\text { relacionados a a } \\
\text { estresse oxidativo. }\end{array}$ & $\begin{array}{l}\text { Avaliar a } \\
\text { gastroproteção de (- } \\
)-\alpha \text {-bisabolol em } \\
\text { modelo de lesões } \\
\text { gástricas induzidas } \\
\text { por etanol. }\end{array}$ & $\begin{array}{l}\text { Os achados } \\
\text { mostram que } \\
(-)-\alpha \text {-bisabolol é } \\
\text { capaz de diminuir } \\
\text { o estresse } \\
\text { oxidativo e o } \\
\text { evento } \\
\text { inflamatório } \\
\text { associado às lesões } \\
\text { induzidas pelo } \\
\text { etanol. }\end{array}$ \\
\hline 3 & $\begin{array}{l}\text { Anti-nociceptive and anti- } \\
\text { inflammatory activities of (-)- } \\
\alpha \text {-bisabolol in rodents } \\
\text { Rocha, Rios, Carvalho, } \\
\text { Cerqueira, Lopes Ade, Leal, } \\
\text { Dias, de Sousa e de Sousa } \\
\text { (2011). }\end{array}$ & $\begin{array}{l}\text { Web of } \\
\text { Science }\end{array}$ & $\begin{array}{l}\text { Pesquisa experimental } \\
\text { in vivo e in vitro, } \\
\text { exploratória,da ação } \\
\text { antiinflamatória } \\
\text { nociceptiva } \\
\text { utilizando modelos } \\
\text { experimentais } \\
\text { clássicos } \\
\text { administração prévia } \\
\text { de alfa-bisabolol, via } \\
\text { oral, nas doses de } 100 \\
\text { e } 200 \mathrm{mg} / \mathrm{Kg} \text { no } \\
\text { modelo de inflamação } \\
\text { e } 25 \text { e } 50 \text { mg / Kg } \\
\text { para o modelo de } \\
\text { nocicepção. }\end{array}$ & $\begin{array}{l}\text { Avaliar o potencial } \\
\text { anti-inflamatório e } \\
\text { anti-nociceptivo do } \\
\text { alfa-bisabolol em } \\
\text { modelos } \\
\text { experimentais } \\
\text { clássicos de } \\
\text { inflamação e dor. }\end{array}$ & $\begin{array}{l}\text { O composto foi } \\
\text { capaz de reduzir a } \\
\text { migração de } \\
\text { leucócitos, edema } \\
\text { e liberação de } \\
\text { TNF- } \alpha \text {, } \\
\text { comprovando sua } \\
\text { atividade periférica } \\
\text { anti-inflamatória e } \\
\text { anti-nociceptiva. }\end{array}$ \\
\hline 4 & $\begin{array}{l}\text { Inhibitory effects of }(-)-\alpha- \\
\text { bisabolol on LPS-induced } \\
\text { inflammatory response in } \\
\text { RAW264.7 macrophages, } \\
\text { Kim, Jung, Kim, Park, Lee e } \\
\text { Park. } \\
(2011) \text {. }\end{array}$ & $\begin{array}{l}\text { Web of } \\
\text { Science }\end{array}$ & $\begin{array}{l}\text { Pesquisa experimental } \\
\text { in vitro. No estudo } \\
\text { foram analisados a } \\
\text { liberação de óxido } \\
\text { nítrico, } \\
\text { prostaglandinas, NF- } \\
\text { kB, por Western } \\
\text { Blotthing,em células } \\
\text { RAW264.7 e ensaio } \\
\text { de atividade do gene } \\
\text { da luciferase. }\end{array}$ & $\begin{array}{l}\text { Investigar os efeitos } \\
\text { antiinflamatórios do } \\
(-)- \\
\text { a-bisabolol e seus } \\
\text { mecanismos de } \\
\text { ação. }\end{array}$ & $\begin{array}{l}\text { Resultados } \\
\text { indicam que (-) -a- } \\
\text { bisabolol exerce } \\
\text { efeitos anti- } \\
\text { inflamatórios por } \\
\text { regulação negativa } \\
\text { da expressão dos } \\
\text { genes iNOS e } \\
\text { COX-2 através da } \\
\text { inibição de NF-jB } \\
\text { e } \\
\text { Sinalização AP-1 } \\
\text { (ERK e p38). }\end{array}$ \\
\hline 5 & $\begin{array}{l}(-)-\alpha \text {-Bisabolol attenuates } \\
\text { visceral nociception and } \\
\text { inflammation in mice } \\
\text { Leite, Leite, Sampaio, } \\
\text { Araruna, De Menezes, Irwin, } \\
\text { Da Costa e Campos. } \\
(2011) \text {. }\end{array}$ & $\begin{array}{l}\text { Web of } \\
\text { Science }\end{array}$ & $\begin{array}{l}\text { Estudo experimental } \\
\text { in vivo. O efeito } \\
\text { antiinflamatório foi } \\
\text { avaliado em modelos } \\
\text { agudos de dermatite } \\
\text { em orelha de } \\
\text { camundongo } r \mathrm{e}\end{array}$ & $\begin{array}{l}\text { Examinar os efeitos } \\
\text { antiinflamatório e } \\
\text { antinociceptivo do } \\
\text { sesquiterpeno } \\
(-) \quad-\quad \alpha \text {-bisabolol } \\
\text { (BISA). }\end{array}$ & $\begin{array}{l}\text { BISA mostrou uma } \\
\text { antinocicepção } \\
\text { significativa não } \\
\text { relacionada com a } \\
\text { dose. } \\
\text { Coletivamente, os } \\
\text { resultados sugerem }\end{array}$ \\
\hline
\end{tabular}




\begin{tabular}{|c|c|c|c|c|c|}
\hline & & & $\begin{array}{l}\text { modelo de nocicepção } \\
\text { visceral. Os animais } \\
\text { foram pré-tratados por } \\
\text { via oral com BISA, e } \\
\text { as respostas } \\
\text { comportamentais } \\
\text { foram analisadas. }\end{array}$ & & $\begin{array}{l}\text { que o BISA pode } \\
\text { ser um agente } \\
\text { antiinflamatório } \\
\text { tópico } \\
\text { antinociceptivo } \\
\text { visceral. }\end{array}$ \\
\hline 6 & $\begin{array}{l}\text { Attenuation of visceral } \\
\text { nociception by } \alpha \text {-bisabolol in } \\
\text { mice: investigation of } \\
\text { mechanisms. } \\
\text { Leite, Fernandes, de } \\
\text { Menezes, Costa e Campos. } \\
(2012) \text {. }\end{array}$ & PubMed & $\begin{array}{l}\text { Pesquisa experimental } \\
\text { in vivo. No presente } \\
\text { trabalho foi utilizado } \\
\text { modelos de lesão } \\
\text { gástrica rara } \\
\text { avaliação para } \\
\text { comportamento } \\
\text { nociceptivo, após a } \\
\text { administração oral de } \\
\text { BISA (50, } 100 \text { e } 200 \\
\text { mg / Kg). }\end{array}$ & $\begin{array}{lr}\text { Examinar o } & \text { efeito } \\
\text { de BISA } & \text { em } \\
\text { modelos } & \text { de } \\
\text { camundongo de } \\
\text { nocicepção visceral }\end{array}$ & $\begin{array}{l}\text { O BISA apresenta } \\
\text { ação } \\
\text { antinociceptiva, } \\
\text { porém os } \\
\text { mecanismos de } \\
\begin{array}{ll}\text { ação ainda são } \\
\text { desconhecidos }\end{array}\end{array}$ \\
\hline 7 & $\begin{array}{l}\text { Evidence for the involvement } \\
\text { of TNF- } \alpha \text { and IL- } 1 \beta \text { in the } \\
\text { antinociceptive and anti- } \\
\text { inflammatory activity of } \\
\text { Stachys lavandulifolia Vahl. } \\
\text { (Lamiaceae) essential oil and } \\
(-) \text { - } \alpha \text {-bisabolol, its main } \\
\text { compound, in mice. } \\
\text { Barreto, Quintans, Amarante, } \\
\text { Nascimento, Amarante, } \\
\text { Barreto, Pereira, Duarte, } \\
\text { Coutinho, Menezes, Zengin, } \\
\text { Aktumsek e Quintans. } \\
\text { (2016). }\end{array}$ & $\begin{array}{l}\text { Web of } \\
\text { Science }\end{array}$ & $\begin{array}{l}\text { Estudo experimental } \\
\text { in vivo. O perfil } \\
\text { antiinflamatório de } \\
\text { EOSl ou } \\
\text { BISA }(50 \mathrm{mg} / \mathrm{kg} \text { ) foi } \\
\text { avaliado pela resposta } \\
\text { inflamatória induzida } \\
\text { por carragenina ( } 2 \% \\
\text { em } 0,2 \mathrm{~mL} \text { ) } \\
\text { em ratos (modelo de } \\
\text { pleurisia). }\end{array}$ & $\begin{array}{l}\text { Estudar os efeitos } \\
\text { antinociceptivos e } \\
\text { antiinflamatórios do } \\
\text { óleo essencial de } S \text {. } \\
\text { lavandulifolia } \\
\text { (EOSl) e (-) - } \alpha- \\
\text { bisabolol (BIS), no } \\
\text { comportamento } \\
\text { nociceptivo } \\
\text { orofacial induzido } \\
\text { por algogênio em } \\
\text { camundongos, e } \\
\text { avaliar o possível } \\
\text { envolvimento de } \\
\text { citocinas pró- } \\
\text { inflamatórias nesses } \\
\text { perfis. }\end{array}$ & 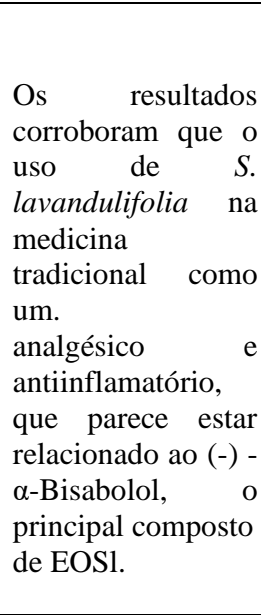 \\
\hline 8 & $\begin{array}{l}\text { Nephroprotective effects of } \\
(-) \quad-\alpha \text {-bisabolol against } \\
\text { ischemic-reperfusion acute } \\
\text { kidney injury. } \\
\text { Sampaio, Menezes, Costa e } \\
\text { Meneses. } \\
(2016) \text {. }\end{array}$ & $\begin{array}{l}\text { Science } \\
\text { Direct }\end{array}$ & $\begin{array}{l}\text { Pesquisa experimental } \\
\text { in vivo. Os animais } \\
\text { foram submetidos à } \\
\text { nefrectomia direita, } \\
\text { seguida de isquemia } \\
\text { com pinçamento da } \\
\text { artéria renal em rim } \\
\text { esquerdo por } 60 \text { min. } \\
\text { e } 48 \text { h de } \\
\text { reperfusão.Após } \\
\text { foram tratados por via } \\
\text { oral com Bis (100 mg } \\
\text { / kg) ou veículo por } \\
24 \text { horas após a } \\
\text { reperfusão e foi feito } \\
\text { a avaliação do } \\
\text { consumo de água, } \\
\text { diurese, osmolalidade } \\
\text { urinária, marcadores } \\
\text { bioquímicos clássicos } \\
\text { e KIM-1 urinário } \\
\text { (molécula de lesão } \\
\text { renal- } 1 \text { ). }\end{array}$ & $\begin{array}{l}\text { Avaliar a atividade } \\
\text { nefroprotetora do (- } \\
\text { ) - } \alpha \text {-bisabolol em } \\
\text { modelos in vivo e } \\
\text { in vitro de } \\
\text { isquemia/ } \\
\text { reperfusão } \\
\text { renal. }\end{array}$ & $\begin{array}{l}\mathrm{O}(-)-\alpha \text {-Bisabolol } \\
\text { tem efeito } \\
\text { nefroprotetor na I / } \\
\mathrm{R} \text { renal, com ação } \\
\text { antioxidante. Além } \\
\text { disso, esse } \\
\text { resultado parece } \\
\text { estar associado a } \\
\text { um efeito protetor } \\
\text { direto sobre o } \\
\text { epitélio tubular. }\end{array}$ \\
\hline 9 & $\begin{array}{l}(-)-\alpha \text {-Bisabolol reduces } \\
\text { orofacial nociceptive } \\
\text { behavior in rodents } \\
\text { Melo, Duailibe, Pessoa, da } \\
\text { Costa, Vieira-Neto, de } \\
\text { Vasconcellos e Campos } \\
(2016) \text {. }\end{array}$ & $\begin{array}{l}\text { Web of } \\
\text { Science }\end{array}$ & $\begin{array}{l}\text { Estudo experimental } \\
\text { in vivo. A dor } \\
\text { orofacial foi induzida } \\
\text { por } \\
\text { Injeção de formalina a } \\
\begin{array}{l}1,5 \% \text { no lábio } \\
\text { superior } \\
\text { camundongos } \\
(20 \mu \mathrm{L}) \text { ou } \\
\text { na articulação }\end{array}\end{array}$ & $\begin{array}{l}\text { Avaliar o efeito } \\
\text { antinociceptivo da } \\
\text { administração oral e } \\
\text { tópica de } \\
(-) \quad-\quad \alpha \text {-bisabolol } \\
\text { (BISA) em modelos } \\
\text { de roedores de } \\
\text { formalina ou } \\
\text { Dor orofacial } \\
\text { induzida por }\end{array}$ & $\begin{array}{l}\text { BISA teve um } \\
\text { efeito } \\
\text { nociceptivo } \\
\text { significativo na dor } \\
\text { orofacial. O efeito } \\
\text { pode ser em parte } \\
\text { devido } \\
\text { antagonismo } \\
\text { TRPA1. } \\
\text { O fato de que o }\end{array}$ \\
\hline
\end{tabular}




\begin{tabular}{|c|c|c|c|c|c|}
\hline & & & $\begin{array}{l}\text { temporomandibular } \\
(\mathrm{ATM}) \text { de ratos (50 } \\
\mu \mathrm{L} \text { ). Administração } \\
\text { prévia tópica (loção) e } \\
\text { por via oral (xarope) } \\
\text { de BISA foram } \\
\text { realizadas antes da } \\
\text { estimulação de dor. A } \\
\text { avaliação } \\
\text { comportamental de } \\
\text { dor foi analisada. }\end{array}$ & $\begin{array}{lr}\text { cinamaldeído } & \mathrm{e} \\
\text { explorar } & \text { os } \\
\text { mecanismos } & \\
\text { inibitórios } & \\
\text { envolvidos. } & \end{array}$ & $\begin{array}{l}\text { efeito do BISA } \\
\text { permaneceu após a } \\
\text { incorporação } \\
\text { em formulações } \\
\text { orais e tópicas } \\
\text { sugere que o } \\
\text { composto } \\
\text { pode ser um } \\
\text { adjuvante útil no } \\
\text { tratamento da dor } \\
\text { orofacial }\end{array}$ \\
\hline 10 & $\begin{array}{l}\text { Cardioprotective effect of (-)- } \\
\alpha \text {-Bisabolol in animal model } \\
\text { of myocardial infarction } \\
\text { Ojha, Azimullah,Taee e } \\
\text { Meeran } \\
\text { (2017). }\end{array}$ & $\begin{array}{l}\text { Web of } \\
\text { Science }\end{array}$ & $\begin{array}{l}\text { Pesquisa experimental } \\
\text { in vivo. O estudo } \\
\text { induziu infarto do } \\
\text { miocárdio, } \\
\text { ratos,através da duas } \\
\text { injeções subcutâneas } \\
\text { de isoproterenol em } \\
\text { intervalo de } 24 \mathrm{~h} . \\
\text { BISA (20 mg / Kg) } \\
\text { foi administrado por } \\
\text { via oral durante } 15 \\
\text { dias. Os níveis de } \\
\text { agentes antioxidantes, } \\
\text { lesões do tecido, } \\
\text { níveis pressóricos e } \\
\text { citocinas aras pró- } \\
\text { inflamatórias foram } \\
\text { analisados. }\end{array}$ & $\begin{array}{l}\text { Investigar } \\
\text { atividade } \\
\text { cardioprotetora } \\
\text { Bisabolol em } \\
\text { modelo animal. }\end{array}$ & $\begin{array}{l}\text { Os resultados } \\
\text { indicam que o } \\
\text { Bisabolol } \\
\text { disponível na dieta } \\
\text { pode ser útil para } \\
\text { prevenir o início e } \\
\text { a progressão da } \\
\text { lesão miocárdica. }\end{array}$ \\
\hline 11 & $\begin{array}{l}\alpha \text {-bisabolol-loaded lipid-core } \\
\text { nanocapsules reduce } \\
\text { lipopolysaccharide-induced } \\
\text { pulmonary inflammation in } \\
\text { mice } \\
\text { D'Almeida, Pacheco de } \\
\text { Oliveira, de Souza, de Sá } \\
\text { Coutinho, Ciambarella, } \\
\text { Gomes, Terroso, Guterres, } \\
\text { Pohlmann, Silva, Martins e } \\
\text { Bernardi } \\
(2017) \text {. }\end{array}$ & PubMed & $\begin{array}{l}\text { Pesquisa } \\
\text { experimental, in vivo. } \\
\text { Qualitativa. } \\
\text { Administração, via } \\
\text { oral, de nanopartícula } \\
\text { acrescida de alfa- } \\
\text { bisabolol em modelo } \\
\text { animal aflição } \\
\text { respiratória aguda } \\
\text { induzida por inalação } \\
\text { de lipopolissacarídeo. }\end{array}$ & $\begin{array}{l}\text { Desenvolver um } \\
\text { sistema de entrega } \\
\text { de drogas usando } \\
\text { nanocápsulas de } \\
\text { núcleo lipídico } \\
\text { (LNCs) para } \\
\text { melhorar os efeitos } \\
\text { antiinflamatórios de } \\
\alpha \text {-bis administrado } \\
\text { por via oral. }\end{array}$ & $\begin{array}{lr}\text { Os resultados } \\
\text { mostram } \\
\text { claramente que } \\
\text { usando LNCs, } \alpha- \\
\text { bis foi capaz de } \\
\text { diminuir } & \text { a } \\
\text { inflamação } & \\
\text { induzida por LPS. }\end{array}$ \\
\hline 12 & $\begin{array}{l}\text { Antinociceptive effect of (-)- } \\
\alpha \text {-bisabolol in nanocapsules } \\
\text { Teixeira, Vieira-Neto, da } \\
\text { Costa, Silva e Campos. } \\
\text { (2017). }\end{array}$ & PubMed & $\begin{array}{l}\text { Pesquisa expeimental } \\
\text { em camundongos } \\
\text { utilizando modelo de } \\
\text { nocicepção corneana e } \\
\text { administração prévia } \\
\text { de nanopartícula } \\
\text { acrescida de } \\
200 \mathrm{mg} / \mathrm{mL} \text { de alfa- } \\
\text { bisabolol. }\end{array}$ & $\begin{array}{l}\text { Desenvolver } r \text { e } \\
\text { avaliar o efeito } \\
\text { antinociceptivo de } \\
\text { um sistema de } \\
\text { liberação } \\
\text { fármacos contendo } \\
(-) \quad-\quad \alpha \text {-bisabolol } \\
\text { (BISA). }\end{array}$ & $\begin{array}{lr}\text { Os resultados } \\
\text { mostraram } & \text { que } \\
\text { animais } & \text { pré- } \\
\text { tratados } & \text { com } \\
\text { BISA-NC } & \text { tiveram } \\
\text { redução } & \\
\text { significativa } & \text { no } \\
\text { número } & \text { de } \\
\text { comportamento } & \\
\text { nociceptivo. } & \end{array}$ \\
\hline 13 & $\begin{array}{l}\text { Corneal antinociceptive } \\
\text { effect of (-)- } \alpha \text {-bisabolol. } \\
\text { Teixeira, Costa e Campos } \\
\text { (2017). }\end{array}$ & PubMed & $\begin{array}{l}\text { Pesquisa experimental } \\
\text { in vivo. A nocicepção } \\
\text { aguda da córnea foi } \\
\text { induzidar com } \\
\text { administração local de } \\
\text { solução salina } \\
\text { hipertônicaem } \\
\text { camundongos } 60 \text { min } \\
\text { após o tratamento } \\
\text { tópico com soluções } \\
\text { ou pomada contendo } \\
\text { BISA } \\
\text { (50 - 200 mg / mL). } \\
\text { O comportamento } \\
\text { nociceptivo por } 30 \\
\text { segundos foi avaliado. }\end{array}$ & $\begin{array}{l}\text { Avaliar a eficácia } \\
\text { antinociceptiva } \\
\text { corneana do BISA e } \\
\text { analisar o melhor } \\
\text { agente } \\
\text { solubilizante. }\end{array}$ & $\begin{array}{l}\mathrm{O} \text { BISA possui } \\
\text { atividade } \\
\text { antinociceptiva da } \\
\text { córnea. }\end{array}$ \\
\hline
\end{tabular}




\begin{tabular}{|c|c|c|c|c|c|}
\hline 14 & $\begin{array}{l}\text { Pharmacological interaction } \\
\text { of } \alpha \text {-bisabolol and diclofenac } \\
\text { on nociception, } \\
\text { inflammation, and gastric } \\
\text { integrity in rats } \\
\text { Ortiz, Cariño-Cortés, Ponce- } \\
\text { Monter, Castañeda- } \\
\text { Hernández e Chávez-Piña. } \\
\text { (2018). }\end{array}$ & PubMed & 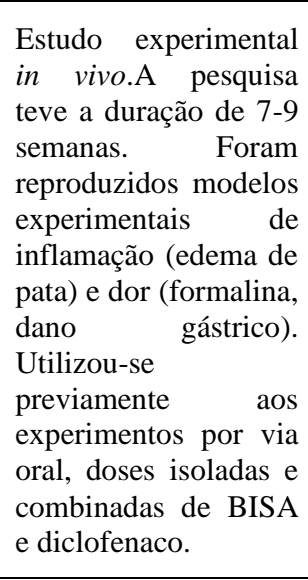 & $\begin{array}{l}\text { Explorar os efeitos } \\
\text { da interação entre } \\
\alpha \text {-bisabolol e } \\
\text { diclofenaco na } \\
\text { inflamação da pata } \\
\text { de rato por injeção } \\
\text { de carragenina, na } \\
\text { nocicepção } \\
\text { induzida por } \\
\text { formalina e na } \\
\text { integridade gástrica } \\
\text { de ratos. }\end{array}$ & $\begin{array}{lr}\text { Os } & \text { autores } \\
\text { concluíram } & \text { que as } \\
\text { interações } & \text { entre } \\
\text { diclofenaco er } & \alpha- \\
\text { bisabolol são } & \text { sinérgicas. Dados } \\
\text { sugerem que as } \\
\text { combinações de } \\
\text { diclofenaco }-\alpha- \\
\text { bisabolol podem } \\
\text { ser uma alternativa } \\
\text { terapêutica segura } \\
\text { para o manejo } \\
\text { clínico rão da } \\
\text { inflamação e / ou } \\
\text { dor inflamatória. }\end{array}$ \\
\hline 15 & $\begin{array}{l}\text { Anti-inflammatory and utero- } \\
\text { relaxant effect of } \alpha \text {-bisabolol } \\
\text { on the pregnant human uterus } \\
\text { Muñoz-Pérez, Ortiz, Ponce- } \\
\text { Monter, Monter-Pérez e } \\
\text { Barragán-Ramírez } \\
\text { (2018). }\end{array}$ & $\begin{array}{l}\text { Web of } \\
\text { Science }\end{array}$ & $\begin{array}{l}\text { Pesquisa experimental } \\
\text { in vitro. Quantitativa. } \\
\text { Dosagens de citocinas } \\
\text { pró-inflamatórias, } \\
\text { TNF } \alpha \text {, Il-1 } \beta \text { e IL-10 } \\
\text { em homogenato de } \\
\text { miométrio humano. } \\
\text { Dosagem de AMPc } \\
\text { por ELISA. }\end{array}$ & $\begin{array}{l}\text { Avaliar a in vitro } \\
\text { efeito } \\
\text { antiinflamatório e } \\
\text { útero-relaxante do } \\
\alpha \text {-bisabolol no } \\
\text { miométrio de } \\
\text { gestantes humanas. }\end{array}$ & $\begin{array}{l}\text { O } \alpha \text {-bisabolol } \\
\text { mostrou ser um } \\
\text { agente adjuvante } \\
\text { potencialmente } \\
\text { seguro e eficaz nos } \\
\text { casos de parto } \\
\text { prematuro, uma } \\
\text { área do tratamento } \\
\text { farmacológico que } \\
\text { requer melhora } \\
\text { urgente. }\end{array}$ \\
\hline 16 & $\begin{array}{l}(-)-\alpha-b i s a b o l o l \\
\text { neuronal damage and } \\
\text { memory deficits through } \\
\text { reduction of proinflammatory } \\
\text { markers induced by } \\
\text { permanent focal cerebral } \\
\text { ischemia in mice. } \\
\text { Fernandes, do Carmo, } \\
\text { Fonteles, Neves, Silva, } \\
\text { Pereira, Ferreira, Lima, } \\
\text { Neves e Andrade. } \\
(2018) \text {. }\end{array}$ & $\begin{array}{l}\text { Web of } \\
\text { Science }\end{array}$ & $\begin{array}{l}\text { Estudo experimental } \\
\text { in vivo. Os animais } \\
\text { foram tratados com } \\
(-)-\alpha \text {-bisabolol (50, } \\
100 \text { e } 200 \mathrm{mg} / \mathrm{kg} / \\
\text { dia, por via oral) ou } \\
\text { veículo ( } 3 \% \text { entre } 80) \\
\text { um dia antes e } 1 \mathrm{~h} \\
\text { após a oclusão da } \\
\text { artéria cerebral. O } \\
\text { tratamento continuou } \\
\text { uma vez por dia } \\
\text { durante cinco dias. }\end{array}$ & $\begin{array}{l}\text { Investigar os efeitos } \\
\text { neuroprotetores do } \\
(-)-\alpha \text {-bisabolol em } \\
\text { camundongos } \\
\text { submetidos à } \\
\text { oclusão permanente } \\
\text { da artéria cerebral } \\
\text { média. }\end{array}$ & $\begin{array}{l}\text { Os } \quad \text { dados } \\
\text { mostraram que o }(- \\
\text { ) - } \alpha \text {-bisabolol } \\
\text { apresenta ação } \\
\text { neuroprotetora } \\
\text { provavelmente } \\
\text { devido à sua } \\
\text { atividade } \\
\text { antiinflamatória, } \\
\text { embora outros } \\
\text { mecanismos não } \\
\text { possam ser } \\
\text { descartados. }\end{array}$ \\
\hline 17 & $\begin{array}{l}\text { Anti-hyperalgesic effect of (- } \\
\text { - } \alpha \text {-bisabolol and }(-)-\alpha- \\
\text { bisabolol } / \beta-\text {-Cyclodextrin } \\
\text { complex in a chronic } \\
\text { inflammatory pain model is } \\
\text { associated with reduced } \\
\text { reactive gliosis and cytokine } \\
\text { modulation } \\
\text { Fontinele, Heimfarth, Pereira, } \\
\text { Rezende, Lima, Barbosa } \\
\text { Gomes de Carvalho, Pires, } \\
\text { Guimarães, Carvalho, } \\
\text { Barreto, Campos, Antoniolli, } \\
\text { Araújo, Quintans-Júnior e } \\
\text { Quintans } \\
(2019) \text {. }\end{array}$ & $\begin{array}{l}\text { Science } \\
\text { Direct }\end{array}$ & $\begin{array}{lr}\text { Pesquisa experimental } \\
\text { in vivo. } \\
\text { Indução de } \\
\text { crônica dor } \\
\text { camundongos } & \text { em } \\
\text { administração } & \text { por } \\
\text { adjuvante (FCA) ou } \\
\text { lesão parcial do nervo } \\
\text { isquiático. } \\
\text { Animais foram } \\
\text { tratados v.o. com } \\
\text { BISA isolado ou em } \\
\text { associação com } \beta- \\
\text { ciclodextrina. }\end{array}$ & $\begin{array}{l}\text { Avaliar o efeito } \\
\text { antinociceptivo e } \\
\text { antiinflamatório do } \\
(-) \quad \alpha \text {-bisabolol } \\
(\text { BIS) isolado e } \\
\text { complexado com } \\
(\beta C D) \text { em modelos } \\
\text { pré-clínicos de dor } \\
\text { crônica. }\end{array}$ & $\begin{array}{l}\text { O BIS e o BIS- } \\
\beta C D \text { têm um efeito } \\
\text { anti-hiperalgésico } \\
\text { em um modelo de } \\
\text { dor inflamatória } \\
\text { crônica, bem como } \\
\text { em um modelo de } \\
\text { dor neuropática. } \\
\text { Assim, concluímos } \\
\text { que o BIS é uma } \\
\text { molécula } \\
\text { promissora para o } \\
\text { tratamento da dor } \\
\text { crônica. }\end{array}$ \\
\hline 18 & $\begin{array}{l}(-)-\alpha \text {-Bisabolol reduces } \\
\text { nociception and central } \\
\text { trigeminal sensitization in } \\
\text { acute orofacial neuropathic } \\
\text { pain induced by infraorbital } \\
\text { nerve injury. } \\
\text { Melo, Panchalingam, } \\
\text { Cherkas, Campos, Avivi- } \\
\text { Arber e Sessle. } \\
(2019) \text {. }\end{array}$ & PubMed & $\begin{array}{l}\text { Pesquisa experimental } \\
\text { in vivo. Foi realizada } \\
\text { transecção do nervo } \\
\text { infraorbital ou } \\
\text { operação simulada em } \\
\text { ratos machos adultos. } \\
\text { A administração de } \\
\text { BISA foi realizado } \\
\text { por via IV no } 7^{\circ} \text { dia } \\
\text { do pós-operatório e } \\
\text { foram feitas as } \\
\text { mensurações da }\end{array}$ & $\begin{array}{l}\text { Examinar se o } \\
(-) \quad-\quad \alpha \text {-bisabolol } \\
\text { (BISA), pode } \\
\text { atenuar } \\
\text { comportamento } \\
\text { nociceptivo e a } \\
\text { sensibilização } \\
\text { central em um } \\
\text { modelo de roedor } \\
\text { de dor neuropática } \\
\text { do trigêmeo. }\end{array}$ & $\begin{array}{l}\text { Os achados } \\
\text { demonstraram que } \\
\text { o BISA pode } \\
\text { atenuar o } \\
\text { comportamento } \\
\text { nociceptivo e a } \\
\text { sensibilização } \\
\text { central em um } \\
\text { modelo } \\
\text { experimental de } \\
\text { dor neuropática } \\
\text { trigeminal aguda. } \\
\end{array}$ \\
\hline
\end{tabular}




\begin{tabular}{|c|c|c|c|c|c|}
\hline & & & $\begin{array}{l}\text { sensibilidade } \\
\text { mecânica facial. }\end{array}$ & & \\
\hline 19 & $\begin{array}{l}\text { Clinical efficacy of new } \alpha \text { - } \\
\text { bisabolol mouthwashes in } \\
\text { postoperative complications } \\
\text { of maxillofacial surgeries: a } \\
\text { randomized, controlled, } \\
\text { triple-blind clinical trial. } \\
\text { Amora-Silva, Ribeiro, } \\
\text { Mendes, Viera-Neto, Abdon, } \\
\text { Costa e Campos } \\
(2019) \text {. }\end{array}$ & $\begin{array}{l}\text { Web of } \\
\text { Science }\end{array}$ & $\begin{array}{l}\text { Ensaio } \text { clínico } \\
\text { randomizado, } \\
\text { controlado e triplo- } \\
\text { cego realizado com } 30 \\
\text { pacientes, submetidos } \\
\text { à cirurgia oral e } \\
\text { maxilofacial. Foram } \\
\text { desenvolvidos três } \\
\text { tipos de enxaguatórios } \\
\text { bucais, baseados em } \\
\text { clorexidina } 0,12 \% \text {, } \\
\text { BISA 0,5 \% e } \\
\text { clorexidina } 0,12 \%+ \\
\text { BISA 0,5 \%. Foram } \\
\text { avaliadas a dor, a } \\
\text { cicatrização e as } \\
\text { infecções no pré e } \\
\text { pós-operatório. }\end{array}$ & $\begin{array}{l}\text { Avaliar a eficácia } \\
\text { dos enxaguatórios } \\
\text { bucais à base de } \alpha- \\
\text { bisabolol (BISA) na } \\
\text { higiene bucal de } \\
\text { pacientes } \\
\text { submetidos } \\
\begin{array}{ll}\text { cirurgia oral è } \\
\text { maxilofacial. }\end{array}\end{array}$ & $\begin{array}{l}\text { Os resultados } \\
\text { indicam que os } \\
\text { enxaguatórios } \\
\text { bucais à base de } \\
\text { BISA apresentam } \\
\text { eficácia clínica, na } \\
\text { melhora da higiene } \\
\text { oral e cicatrização } \\
\text { de feridas, bem } \\
\text { como na redução } \\
\text { da dor pós- } \\
\text { operatória. }\end{array}$ \\
\hline 20 & $\begin{array}{l}\alpha \text {-Bisabolol, a Dietary } \\
\text { Bioactive Phytochemical } \\
\text { Attenuates Dopaminergic } \\
\text { Neurodegeneration through } \\
\text { Modulation of Oxidative } \\
\text { Stress, Neuroinflammation } \\
\text { and Apoptosis in Rotenone- } \\
\text { Induced Rat Model of } \\
\text { Parkinson's disease. } \\
\text { Javed, Meeran, Azimullah, } \\
\text { Bader Eddin, Dwivedi, Jha e } \\
\text { Ojha. } \\
(2019) \text {. }\end{array}$ & PubMed & 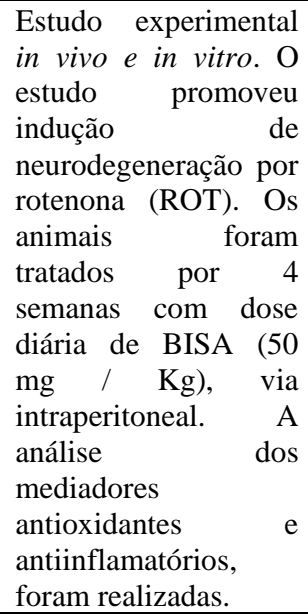 & $\begin{array}{l}\text { Investigar os efeitos } \\
\text { neuroprotetores } \\
\text { do BISA. }\end{array}$ & $\begin{array}{l}\text { Os resultados do } \\
\text { estudo são } \\
\text { sugestivos para os } \\
\text { efeitos } \\
\text { neuroprotetores do } \\
\text { BISA por meio de } \\
\text { propriedades } \\
\text { antioxidante, } \\
\text { antiinflamatória e } \\
\text { antiapoptóticas em } \\
\text { modelo de Doença } \\
\text { de Parkinson } \\
\text { induzido por ROT. }\end{array}$ \\
\hline 21 & $\begin{array}{l}\text { Pharmacological properties } \\
\text { of } \alpha \text { - Bisabolol Sesquiterpen: } \\
\text { a brief review } \\
\text { Souza, Gomes, Cruz, Santos } \\
\text { e Oliveira Filho } \\
\text { (2019). }\end{array}$ & PubMed & $\begin{array}{l}\text { Revisão de literatura. } \\
\text { Pesquisa sobre o } \\
\text { potencial } \\
\text { farmacológico do } \\
\text { alfa-bisabolol. }\end{array}$ & $\begin{array}{l}\text { Realizar uma } \\
\text { revisão de literatura } \\
\text { sobre as } \\
\text { propriedades } \\
\text { farmacológicas do } \alpha \\
\text { - bisabolol e sua } \\
\text { aplicação como } \\
\text { alternativa para o } \\
\text { tratamento das mais } \\
\text { diversas patologias } \\
\text { que podem } \\
\text { acometer o ser } \\
\text { humano. }\end{array}$ & 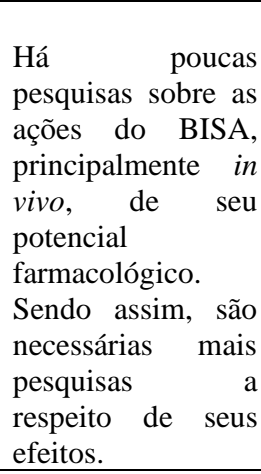 \\
\hline 22 & $\begin{array}{l}\alpha-\text { Bisabolol suppresses the } \\
\text { inflammatory response and } \\
\text { ECM catabolism in advanced } \\
\text { glycation end products- } \\
\text { treated chondrocytes and } \\
\text { attenuates murine } \\
\text { osteoarthritis. } \\
\text { Xu, Sheng, Dou, Chen, Zhou } \\
\text { e Lin, Yang } \\
(2020) \text {. }\end{array}$ & PubMed & $\begin{array}{l}\text { Pesquisa experimental } \\
\text { in vitro. Foram } \\
\text { isolados condrócitos } \\
\text { humanos com modelo } \\
\text { de osteoartrite (OA), } \\
\text { tratados com BISA. }\end{array}$ & $\begin{array}{l}\text { Avaliar o efeito } \\
\text { antiinflamatório e } \\
\text { condroprotetor do } \\
\text { BISA na progressão } \\
\text { da osteoartrite e } \\
\text { explorar seu } \\
\text { mecanismo } \\
\text { subjacente. }\end{array}$ & $\begin{array}{l}\text { O tratamento com } \\
\text { BISA foi capaz de } \\
\text { suprimir } \\
\text { inflamação na OA } \\
\text { e pode ser utilizado } \\
\text { como r terapia } \\
\text { auxiliar no } \\
\text { tratamento da OA. }\end{array}$ \\
\hline 23 & $\begin{array}{l}\text { Effect of (-) - } \alpha \text {-Bisabolol on } \\
\text { the Inflammatory Response } \\
\text { in Systemic Infection } \\
\text { Experimental Model in } \\
\text { C57BL/6 Mice. } \\
\text { Cavalcante, Silva-Filho, } \\
\text { Wiirzler, Cardia, Uchida, } \\
\text { Silva-Comar, Bersani-Amado }\end{array}$ & PubMed & $\begin{array}{l}\text { Pesquisa experimental } \\
\text { in vivo e in vitro. } \\
\text { Foram feitos ensaios } \\
\text { para avaliar a } \\
\text { viabilidade celular e } \\
\text { atividade fagocítica } \\
\text { de neutrófilos in vitro. } \\
\text { Foi induzido sepse }\end{array}$ & $\begin{array}{l}\text { Avaliar o efeito do } \\
\text { BISA na resposta } \\
\text { inflamatória e na } \\
\text { taxa } \\
\text { sobrevivência em } \\
\text { um modelo de } \\
\text { infecção sistêmica, } \\
\text { e na atividade }\end{array}$ & $\begin{array}{lrr}\text { Os resultados } \\
\text { sugerem que } \\
\text { BISA apresenta } \\
\text { atividade } & \text { na } \\
\text { quimiotaxia } & \\
\text { leucocitária e } & \text { na } \\
\text { produção de } & \mathrm{NO} \text {, } \\
\text { além de mostrar }\end{array}$ \\
\hline
\end{tabular}




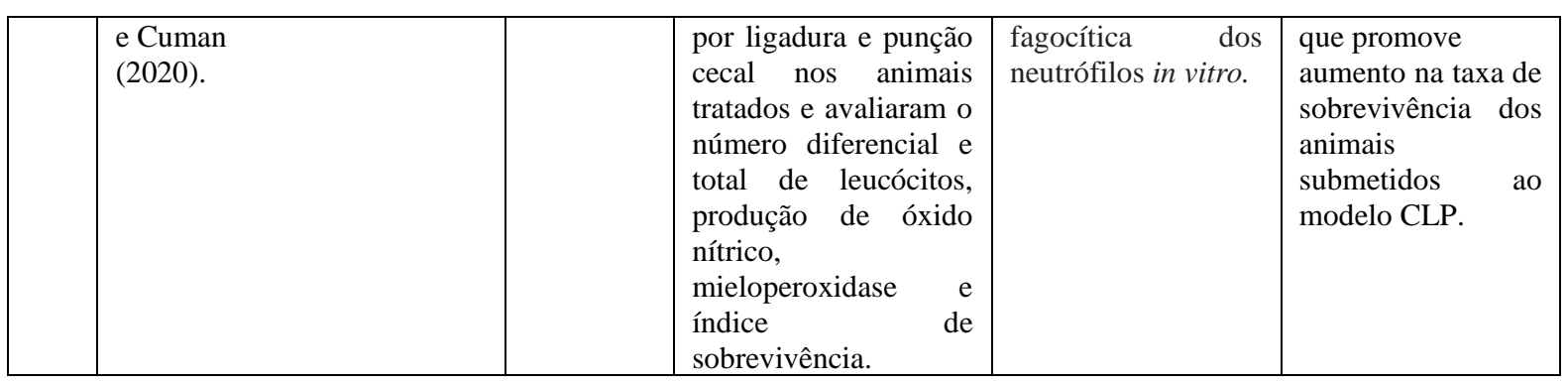

Fonte: Autores (2021).

Durante a produção da revisão integrativa, podemos perceber que o maior número de publicações sobre o BISA, se relaciona com sua potencial atividade sobre os mecanismos envolvidos no processo inflamatório, totalizando 22 produções $(59.45 \%)$ das 37 selecionadas. Tais resultados podem ser encontrados no Quadro 2, onde estão apresentados o nome dos autores, ano de publicação, título do estudo, a metodologia empregada, os objetivos da pesquisa e a conclusão dos trabalhos. Dos 21 artigos selecionados, 5 deles foram publicados no período de 2017 (23,80\%), sendo esse o ano com o maior número de pesquisas, que investigam as ações do BISA sobre as fases da inflamação. Os períodos de 2011, 2017 e 2019 se caracterizaram como os anos de $2^{\circ}$ lugar em publicações $(n=4)$, perfazendo $11,11 \%$ do acervo dos artigos sobre as ações antinociceptiva e antiinflamatória do terpenóide. Os anos de 2016, 2018 e 2020, seguiram com 5,55 \% (n=2), 8.338 \% (n=3) e $5.55 \%$ ( $\mathrm{n}=2) \mathrm{em}$ número de investigações sobre o alfa-bisabolol e sua atividade antiflogística, perfazendo $19.44 \%$ dos artigos (n=7), nos respectivos períodos. É interessante observar que dos 10 trabalhos publicados nesses anos, 8 deles (80\%) utilizaram, como metodologia, a pesquisa experimental in vivo, empregando roedores. Entre os protocolos experimentais que avaliaram a capacidade antinociceptiva, antiinflamatória e antioxidante, os autores usaram como desafio a pleurisia $(\mathrm{n}=1)$, as lesões por reperfusão $(n=2)$, o edema de pata e dor orofacial $(n=1)$, septicemia $(n=1)$ além de modelos que reproduzem situações clínicas de dor crônica ( $\mathrm{n}=1)$ e dor neuropática $(\mathrm{n}=2)$. O artigo publicado por Carvalho et al. (2018), mostra que a dor crônica no Brasil, já constitui um problema de saúde pública, e afeta dois terços da população. Os autores referem que essa condição, é de alta prevalência e severidade em nosso país. Desta forma, tais estudos tornam-se imperativos e devem ser estimulados. Outra observação pertinente das publicações, está no fato dos modelos empregados, também analisarem a atividade antioxidante do BISA, uma vez que já está bem estabelecida a íntima relação entre os produtos do estresse oxidativo e a ativação de vias próinflamatórias nos diversos tecidos (McGarry et al., 2018).

O interesse em investigar a bioatividade do BISA sobre condições clínicas, que promovem inflamação e produção de radicais livres, foi explorada por Rocha et al. (2010), entre outros. Os autores utilizaram um modelo animal que reproduz quadro de úlcera gástrica, por mecanismos distintos. Um dos modelos (indometacina), reproduz a condição de ulceração por inibição da produção de prostaglandina (PGE2) de ação gastroprotetora, e o outro por ação direta do etanol (radicais livres) sobre a mucosa gástrica. Ambos apresentam mecanismos lesivos bem esclarecidos e se relacionam com o aumento da permeabilidade celular e inibição das enzimas cicloxigenases (COX), e com o aumento de ânions superóxido, radicais hidroxila e peroxidação lipídica, induzido pelo estresse oxidativo (Glavin \& Szabo, 1992; Repetto \& Llsuy, 2002; Wallace, 2008). O uso preventivo, por via oral, de doses de 100 e $200 \mathrm{mg} / \mathrm{Kg}$ de BISA, foi capaz de proteger a mucosa gástrica dos animais em ambas as simulações supracitadas. Durante os experimentos, os autores desafiaram os animais tratados com o bioativo, através da administração intraperitoneal de agentes ulcerativos (L-NAME $10 \mathrm{mg} / \mathrm{Kg}$; glibenclamida $10 \mathrm{mg} / \mathrm{Kg}$ e indometacina $10 \mathrm{mg} / \mathrm{Kg}$ ). Entretanto, o desafio com os compostos não foi capaz de reverter a gastroproteção proporcionada pelo BISA. Nesse estudo, também foram analisadas as dosagens de glutationa reduzida (GSH), do conteúdo gástrico dos animais. Todos os animais com lesão gástrica sem tratamento, mostraram níveis reduzidos de grupos sulfidrila, gerando assim um ambiente propício para a produção de radicais livres. Em contrapartida, os animais tratados com o $\alpha$ - bisabolol tiverem os 
níveis de grupos sulfidrila aumentados, sugerindo assim que, o aumento da biodisponibilidade desses compostos possa estar envolvido com o mecanismo de gastroproteção, observado nos animais em uso de BISA.

No que se diz respeito à avaliação do BISA sobre a inibição da inflamação, Kim et al. (2011) desenvolveram ensaios in vitro com células RAW264.7, e observaram que o terpenóide inibiu a produção de óxido nítrico e PGE2, por consequência da redução da expressão dos genes iNOS e COX-2. As vias promotoras de sinalização pró-inflamatória, envolvidas nesse mecanismo são a ERK e p38, as quais foram bloqueadas pelo BISA. Há evidências indicando que o $\alpha$ - bisabolol pode diminuir a produção de eicosanóides pró-inflamatórios, a quimiotaxia e a permeabilidade vascular (Leite et al., 2011).

Sobre a potencial ação antinociceptiva do $\alpha$ - bisabolol, foram elegidos para essa revisão, 9 artigos no total (14.06 \%). Todos os pesquisadores utilizaram modelos clássicos de indução de dor nociceptiva (periférica) ou neuropática pela administração de substâncias algogênicas, como por exemplo, carragenina (CAR), dextrana (DXT), óleo de cróton (OC), óleo de mostarda, formalina, entre outros.

Foram publicados no ano de 2011, 2 artigos (Rocha et al., 2011; Leite et al., 2011) sobre o provável efeito antinociceptivo do BISA, em modelos experimentais de dor periférica. Nos estudos de Rocha et al. (2011) a administração por gavagem nas doses de 100 e $200 \mathrm{mg} / \mathrm{Kg}$, em animais com edema de pata induzido por carragenina e dextrana, foi capaz de reduzir o inchaço de forma significativa, quando comparados ao grupo controle. Adicionalmente, os autores observaram que o composto estudado, também reduziu o edema de pata em modelos induzidos por 5-HT. Porém, não foi capaz de reproduzir o mesmo efeito sobre edema de pata provocado por histamina. Já nos modelos de nocicepção visceral, induzida por ácido acético e dor periférica induzida por administração intraplantar de formalina, nas doses de 25 e $50 \mathrm{mg} / \mathrm{Kg}$, o $\alpha$-bisabolol promoveu ação antinociceptiva. Entretanto, esse estudo sugere que o bioativo não tem ação sobre dores aliciadas por mecanismos térmicos (placa quente), mas diminui a hipernocicepção provocada por mecanismos mecânicos (carragenina). Reunindo todos os dados, os autores sugerem que as ações antinociceptivas do BISA não se relacionam com vias neuronais de dor, mas sim com interferência nas respostas inflamatórias locais, uma vez que diminuem a migração de leucócitos, a degranulação de neutrófilos e a produção de TNF- $\alpha$ na periferia.

Adicionalmente, Rocha et al. (2011), utilizando modelo de lesão gástrica, por estresse oxidativo (etanol), analisou a atividade de enzimas envolvidas nos mecanismos de proteção e produção de radicais livres (mieloperoxidase, superóxido dismutase e catalase), bem como, os produtos formadores e finais do estresse oxidativo, tais como: a peroxidação de lipídeos de membrana e a produção de nitritos. Os resultados do estudo evidenciaram que, o (-) $\alpha$ - bisabolol foi capaz de aumentar a atividade da superóxido dismutase, diminuir a peroxidação lipídica, reduzir a atividade da catalase e mitigar o influxo de células inflamatórias na mucosa gástrica. Desta forma, as lesões nos animais tratados foram mínimas, pela diminuição do estresse oxidativo e processo inflamatório.

Tais publicações foram o "ponta pé" para outras avaliações sobre o tema. Leite et al. (2012), reproduziram protocolos de dor visceral e dermatite em camundongos. Em ambas avaliações, as dosagens utilizadas de BISA foram de 50, 100 e 200 $\mathrm{mg} / \mathrm{Kg}$ por via oral em modelo de pleurisia ou injeção intracolônica em camundongos, induzidas por mecanismos agentes algogênicos distintos. Os resultados mostraram a efetividade do BISA como agente antinociceptivo visceral e tal efeito não é de forma dose-dependente, além disso foi eficaz em inibir a dermatite induzida por todos os agentes nocivos empregados no estudo, incluindo a capsaicina (agonista do TRPV1). Os dados foram baseados na coleta de informações sobre o comportamento nociceptivo dos animais pré-tratados com o bioativo. Ademais, Leite et al. (2012), referem que foram realizados estudos sobre o envolvimento dos receptores nitrérgicos, noradrenérgicos, $\mathrm{K}_{\mathrm{ATP}}, 5-\mathrm{HT}_{3}$ e TRPV 1 no efeito do BISA sobre a sensação dolorosa. Sendo assim, os animais foram tratados com L-NAME (10 mg / kg, ip), ioimbina (2 mg / kg, ip), glibenclamida (5 mg / kg, ip), ondansetron (10 mg / kg, ip) ou vermelho de rutênio ( $3 \mathrm{mg} / \mathrm{kg}, \mathrm{sc}), 30$ minutos antes da administração de BISA $(50 \mathrm{mg} / \mathrm{kg}$ ). Os resultados revelaram que tais agentes não foram capazes de reverter o efeito 
antinociceptivo da droga natural, porém os testes foram inconclusivos e há necessidade de maiores investigações para elucidação dos reais mecanismos inibitórios do BISA na dor.

Entre os anos de 2011 a 2016, há um hiato nas publicações sobre as ações antiflogísticas do BISA. Os autores Barreto et al. (2016) e Melo et al. (2016) retomam as pesquisas sobre os mecanismos da antinocicepção e anti-inflamatória do terpenóide, reproduzindo modelos experimentais em camundongos. Os dois autores objetivaram avaliar a ação do $\alpha$-bisabolol sobre o comportamento nociceptivo, de dor orofacial induzida por algogênicos. Entretanto, foram utilizadas diferentes doses de BISA. Barreto et al (2016) utilizou o pó nas concentrações de 25 e $50 \mathrm{mg} / \mathrm{Kg}$ e promoveu a indução de dor, por administração de formalina $20 \mu \mathrm{L}(2 \%)$, capsaicina $(20 \mu \mathrm{l}, 2,5 \mu \mathrm{g})$ e glutamato $(20 \mu \mathrm{l}, 25 \mathrm{Mm})$ no lábio superior direito dos animais. Os resultados mostraram que o tratamento prévio com BISA foi eficaz em todos os testes de dor, inclusive no teste de formalina, na fase neurogênico (primeira fase) e na fase inflamatória (segunda fase). Melo et al. (2016) utilizaram o pó de BISA nas doses de 100, 200 e 400 mg / Kg, e produziram uma loção e xarope do terpenóide nas concentrações de 50, 100 e 200 mg / Kg. A dor orofacial foi impelida por administração de formalina e cinamaldeído no lábio superior ou articulação temporomandibular. A conclusão dos autores foi de que o BISA pode ser um útil adjuvante no tratamento de dor orofacial, pois o efeito pode estar associado ao antagonismo dos receptores TRPV1, devido à alta afinidade de ligação do composto por tais receptores, observada durante o estudo de docking molecular utilizando HC-030031 (antagonista do receptor de TRPV1).

Ainda em 2016, Barreto et al. (2016) apontaram em seus estudos, que o uso de BISA em modelo animal de pleurisia, foi capaz de promover uma marcante redução dos níveis de TNF- $\alpha$ e de IL-1 $\beta$, evidenciando sua significativa atividade antiinflamatória.

O modelo experimental de lesão renal aguda (I/R), provocada por nefrectomia seguida de clampagem da artéria renal, gera isquemia local, e a reperfusão, após 60 minutos, é capaz de promover estresse oxidativo importante. Tal protocolo vem sendo utilizado para estudar os mecanismos envolvidos na ação antioxidante de várias drogas vegetais (Torres-González et al., 2018; Hussien et al., 2020).

O tratamento via oral, em ratos, com $100 \mathrm{mg} / \mathrm{Kg}$ de BISA por 24 horas, após a indução de I/R, protegeu o tecido renal dos danos causados pela ação de radicais livres. Parâmetros como diurese, ingestão hídrica, osmolaridade urinária, níveis de creatinina, ureia, ácido úrico, depuração da creatinina, proteinúria, níveis de KIM-1 e mucroalbuminúria estavam significativamente melhores, quando comparados ao controle. Os dados foram de encontro com a avaliação histológica do tecido renal, onde pode-se observar melhora marcante sobre a congestão vascular e depósitos proteicos intratubulares. Ademais, os autores relatam menores níveis de TBARS (ácido tiobarbitúrico) e GSH nos tecidos dos animais tratados (Sampaio et al., 2016).

Posteriormente, Ojha et al. (2017) e Javed et al. (2019), contribuíram com esses achados, pois os pesquisadores objetivaram seus estudos para a elucidação dos prováveis mecanismos, envolvidos na ação antioxidante do bioativo.

Nos estudos de Ojha et al. (2017), essas afirmações acerca da capacidade do BISA, em inibir a ação de radicais livres foi confirmada. O tratamento por 15 dias com (-) - $\alpha$ - bisabolol $(20 \mathrm{mg} / \mathrm{Kg}$ ), em modelo animal de infarto do miocárdio, reproduziu os mesmos resultados. Os animais tratados tiveram aumento da atividade das enzimas antioxidantes, assim como houve restauração da atividade de enzimas do miocárdio e inibição da peroxidação lipídica. O desfecho das análises, revelaram menor processo inflamatório por redução da produção de citocinas pró-inflamatórias, resultando em mionecrose, edema e infiltração neutrofílica diminuída.

O estudo dirigido por Teixeira et al. (2017) se embasou na busca de nanossistemas que melhoram a biodisponibilidade e estabilidade de óleos essenciais e por consequência, otimizam a ação farmacológica do mesmo. Logo, o objetivo da pesquisa foi avaliar a eficácia da ação antinociceptiva de nanopartículas adicionadas de BISA em modelo de dor por ativação de receptores TRPV1, uma vez que o mesmo grupo de pesquisadores propôs que a bioatividade de inibição da dor pelo 
sesquiterpeno, se dá por antagonismo desses receptores. O modelo de dor corneana foi o elegível, pois há densa inervação nesse tecido e grande população de receptores TRPV1. Além disso, estudos mostram que a indução nociceptiva na córnea, ativa transitoriamente os neurônios WDR (nociceptivos) no subnúcleo caudal do trigêmeo (Carstens, Kuenzler \& Handwerker, 1998), sendo então útil em estudos sobre dor orofacial. Os achados do estudo colaboram com a tese de que a provável ação do BISA, nesse tipo de modelo, se dá pelo bloqueio dos receptores supracitados e também, pelo bloqueio irreversível dos canais de sódio voltagem - dependentes (Alves et al., 2010).

Nos anos subsequentes, Ortiz et al. (2018) e Fontinele et al. (2018), promoveram estudos que corroboram com os resultados anteriores.

A diminuição dos níveis de TNF- $\alpha$ e de IL- $1 \beta$, em experimentos de atividade antiinflamatória do BISA, foram reforçadas por um estudo que utilizou um modelo in vitro, de amostras de miométrio humano de grávidas (Munõz- Pérez et al., 2018). Em outro estudo realizado por Fontinele et al. (2018), utilizando modelo de dor por inflamação crônica, através da ativação da resposta adaptativa do sistema imune ou lesão parcial do nervo isquiático, o tratamento prévio com $50 \mathrm{mg} / \mathrm{Kg}$ de BISA ou BISA plus $\beta$-ciclodextrina, contribui com a afirmação dos demais, em relação à inibição da produção de TNF- $\alpha \mathrm{e}$ acrescentam ao efeito, a capacidade do bioativo em estimular a produção de citocinas anti-inflamatórias (IL-10), modular a liberação de citocinas e inibir a expressão de Iba-1 glial, marcador de injúria neuronal.

Em uma avaliação comparativa da ação analgésica, inflamatória e dano gástrico da combinação ou uso isolado de $\alpha$ bisabolol e diclofenaco , um anti-inflamatório não esteroidal (AINE), revelou que as ações antiflogísticas do AINE e do BISA são sinérgicas, porém a administração sistêmica de BISA isolado, promoveu inibição da dor e da inflamação, sem produção de dano gástrico. O uso da combinação BISA/diclofenaco, diminuiu o efeito de dano no tecido gástrico. Sendo assim, tal associação pode contribuir para o tratamento de dores crônicas com menores efeitos colaterais (Ortiz et al., 2018).

Javed et al. (2019) estudaram o efeito da administração intraperitoneal de $50 \mathrm{mg} / \mathrm{kg}$ de BISA, por 4 semanas, em modelo experimental de Doença de Parkinson (DP) induzida por rotenona (ROT), em ratos. A administração de ROT perturba o equilíbrio antioxidante - oxidante no sistema nervoso central (SNC), que contribui para a instalação de neuroinflamação e neurodegeneração dopaminérgica, observados no início da DP. A patogenicidade da ROT no SNC se caracteriza por estresse oxidativo, inflamação e apoptose. O uso de BISA preveniu significativamente, a perda de neurônios dopaminérgicos e fibras na substância negra e estriado. Os autores relacionam o efeito protetor, a capacidade do bioativo em inibir o estresse oxidativo, induzido pela ROT, pela capacidade de restaurar o MC-I mitocondrial, bem como por melhorar a atividade das enzimas superóxido dismutase e catalase (enzimas antioxidantes). Adicionalmente, atenuou a ativação de células da glia, inibiu a liberação de citocinas pró-inflamatórias (IL-1 $\beta$, Il-6 e TNF- $\alpha$ ) e mediadores inflamatórios (iNOS e COX-2) no estriado. As análises de neurônios dopaminérgicos, evidenciaram menor número de células em apoptose nos animais tratados, através da regulação positiva de proteínas antiapoptóticas (Bcl-2) e negativas de proteínas pró-apoptóticas (Bax, caspases 3 e 9 clivadas).

Fernandes et al. (2019) realizaram uma pesquisa sobre o efeito do $\alpha$ - bisabolol no modelo de isquemia cerebral focal em camundongos, embora haja escasses de estudos sobre esse tema. Os autores obtiveram resultados significativos com a administração oral de BISA (50, 100 e $200 \mathrm{mg} / \mathrm{Kg}$ ) por 5 dias, após a oclusão permanente da artéria cerebral média. Os autores sugerem que as doses de 100 e $200 \mathrm{mg} / \mathrm{Kg}$ de BISA foram capazes de reduzir substancialmente a área de infarto e os déficits neurológicos causados pelo modelo experimental. Acrescenta que a maior dosagem (200 mg / Kg), melhorou a viabilidade celular e reduziu a astrogliose e também a degeneração neuronal da região afetada. Os testes de atividade motora, memória e cognição foram melhorados no grupo tratado, em comparação ao grupo controle. As análises in vitro do córtex temporal e estriado, evidenciaram aumento da atividade da MPO, iNOS e da imunorreatividade no TNF- $\alpha$ nessas áreas. Sendo assim, concluiu-se que o BISA apresenta atividade neuroprotetora e pode ser uma alternativa terapêtica no tratamento de doenças neurodegenerativas e no acidente vascular encefálico. 
Um ensaio clínico randomizado, controlado e triplo-cego foi desenvolvido por Amora-Silva et al. (2019), o qual analisou a eficácia de uma preparação galênica contendo BISA $0.5 \%$ (enxaguatório bucal), sobre os efeitos pós-operatórios de 30 pacientes, submetidos à cirurgia orofacial e maxilofacial. $\mathrm{O}$ uso do produto 2 vezes ao dia, por 15 dias, mostrou eficácia comparativa ao enxaguatório padrão (clorexidina $0,12 \%$ ), recomendado nessas situações. Os autores referem que a associação de clorexidina e BISA resultaram em melhora aparente, mas não estatística, da manifestação da dor pós-operatória, cicatrização de feridas e melhora de higiene bucal, nesse grupo em particular. Desta forma, pode servir como um substituto da clorexidina $0.12 \%$ em cirurgias bucomaxilofaciais.

Os achados de Cavalcante et al. (2020) colaboram com os resultados dos autores anteriores, uma vez que o estudo mostra que o composto foi capaz de diminuir a quimiotaxia de polimorfonucleares em modelo animal de peritonite. Tal efeito é dose dependente $(50$ e $100 \mathrm{mg} / \mathrm{Kg}$ ). A pesquisa do efeito do BISA sobre a produção de NO, mostrou que a dose de $200 \mathrm{mg} /$ $\mathrm{Kg}$, foi capaz de aumentar os níveis de nitrito no exsudato peritoneal. As doses de 50 e $100 \mathrm{mg} / \mathrm{Kg}$ de BISA, influenciaram a atividade da MPO, sendo observado um aumento de 35 e $50 \%$, respectivamente, de sua função nos animais tratados.

Dando seguimento aos estudos em condições de inflamação e dor crônica, Xu et al. (2020) desenvolveram um modelo de osteoartrite (OA) para testar a capacidade antiinflamatória e condroprotetora do BISA. A pesquisa se torna interessante, pois os autores além de avaliar a capacidade antiinflamatória do BISA sobre a sinalização de citocinas, também desafia o composto frente a situações de lesão tecidual inerentes ao envelhecimento, pela deposição de AGEs (produtos finais de glicação avançada). O estudo foi conduzido em duas fases, in vitro, pela análise de condrócitos humanos pré tratados com BISA (2,5, 5, $10 \mu \mathrm{M})$ por $24 \mathrm{~h}$ e sendo expostos à AGEs. A outra fase, in vivo, foi realizada através de modelo experimental cirúrgico de osteoartrite (lesão de menisco medial) e tratamento prévio com $30 \mathrm{mg}$ / Kg de BISA em camundongos. Os achados da primeira fase (in vitro) mostraram que o pré-tratamento com BISA foi capaz de suprimir a reação inflamatória induzida por AGE, e em adição inibiram a degeneração da matriz extracelular (ECM) por mecanismos que sugerem o bloqueio da sinalização do fator nuclear kappa B (NF-kB), p38 e c-Jun N-terminal quinase (JNK). Já os resultados da segunda fase (in vivo) evidenciaram que a administração de BISA melhorou as alterações radiológicas e histopatológicas induzidas por lesão do menisco medial, em relação ao grupo controle, e resultou em melhores pontuações ultrassonográficas de OA de joelho (pontuação OARSI).

Analisando os artigos, pode-se inferir que a ação analgésica do BISA é primordialmente em nível periférico e está diretamente ligada a propriedades anti-inflamatórias (Rocha et al., 2011; Kim et al., 2011; Leite et al., 2011; Barreto et al., 2016, Werner et al., 2017; Ortiz et al., 2018; Muñoz-Pérez et al., 2018; Fernandes et al., 2018; Xu et al., 2020).

\section{Conclusão}

O consumo de camomila (Matricaria chamomilla) em nosso país é de grande aceitação por suas características organolépticas e bioativas. Há inclusive, a inserção da espécie vegetal em preparações fitoterápicas indicadas pelo SUS e faz parte, na $16^{\mathrm{a}}$ citação, da Relação Nacional de Plantas Medicinais de Interesse ao Sistema Único de Saúde (RENISUS), a qual faz parte da Política e Programa Nacional de Plantas Medicinais e Fitoterápicos (Brasil, 2016). Sendo assim, as pesquisas com a droga vegetal têm sido incentivadas pelo governo de nosso país. É sabido que o uso de óleos essenciais de plantas com potencial farmacológico, são mais indicados para a pesquisa, por serem mais puros, e por isso de melhor elucidação dos mecanismos que envolvem sua ação farmacológica. Reunindo essas informações, o BISA tornou-se assunto de grande interesse científico por apresentar várias vantagens em seu estudo e por sua comprovada atividade contra diversas enfermidades, tais como efeito calmante, antialérgico, antibactericida, anti-inflamatório, antineoplásico, antioxidante, hepatoprotetor, analgésico, entre outros. Portanto, o estudo da eficácia do uso terapêutico de BISA como droga natural alternativa ou adjuvante em situações clínicas inflamatórias (agudas ou crônicas) e álgicas, que imponham tratamentos farmacológicos prolongados e que tragam efeitos adversos importantes e prejudiquem a qualidade de vida do usuário e sua 
aderência ao tratamento, são imperativos. Logo, essa revisão de literatura teve o intuito de auxiliar na compilação de dados referentes ao uso do óleo essencial da camomila, $\alpha$ - bisabolol, em diversas situações que requeriam suas propriedades antiinflamatórias, marcadas por seus sinais cardinais (dor, edema, rubor e calor) e metabólicos (estresse oxidativo). Em quase sua totalidade, os artigos selecionados mostram a eficácia do composto isolado ou em associações, nas condições de inflamação, dor e edema. Porém, fica evidente que são necessários maiores esclarecimentos sobre os mecanismos de ação, e há pouca investigação de qualidade sobre suas ações no tecido tegumentar. Ademais, falta escopo para estabelecimento da dosagem mínima efetiva nos estudos in vivo e in vitro. Podemos também observar, que há discrepância de resultados sobre o efeito dose-dependente, o que gera dúvidas sobre as preparações e seu impacto no caso de uso contínuo e por longo prazo. Para finalizar, os autores concluem que há uma promissora utilização terapêutica do BISA em quadros de inflamação, e que mais estudos devem ser empregados para preencher as lacunas identificadas nessa revisão.

\section{Agradecimentos}

Agradecemos à Universidade Cesumar, em especial ao Departamento de Medicina, pelo incentivo e total apoio a esta pesquisa. Agradeço também aos integrantes do Programa de Ciências Farmacêuticas e do Laboratório de Inflamação.

\section{Referências}

Abdulkhaleq, L. A., Assi M. A., Abdullah R., Zamri-Saad M., Taufiq-Yap Y. H., \& Hezmee, M. N. M. (2018). The crucial roles of inflammatory mediators in inflammation: A review. Veterinary World.,11(5):627-635. https://doi.org/ 10.14202

Alves, A. M. H., Gonçalves, J. C., Cruz, J. S. R., \& Araújo, D. A. M. (2010). Avaliação do sesquiterpeno (-) alfa-bisabolol como um novo bloqueador nervoso periférico. Neuroscience. Letters. 472(1), 11-15.

Amora-Silva, B. F., Ribeiro, S. C., Vieira, C. L. F., Mendes, R., Vieira-Neto, A. E., Abdon, A. P. V., Costa, F.N., \& Camposet. A. R. (2019). Clinical efficacy of new $\alpha$-bisabolol mouthwashes in postoperative complications of maxillofacial surgeries: a randomized, controlled, triple-blind clinical trial. Clinical Oral Investigation, 23, 577-584. http://doi.org/ 10.1007 / s00784-018-2464-4

Araújo, M. C., dos Santos, H. R., de Sousa, F. A. G.., Feitosa, J. V., \& Martins, C. J. G. (2015). Content, Yield and quality of essential oil Vanillosmopsis arborea (Gardner) Baker (candeeiro) and its allelopathy, Revista Cubana de Plantas Medicinales, 20(1), 131-141.

Bardin, L. (2011). Análise de conteúdo. Editora 70, 288.

Barreto, R. S. S., Quintans, J. S. S, Amarante, R. K. L., Nascimento, T. S., Amarante, R. S., Barreto, A. S., Pereira. E. W. M., Duarte, M. C., Coutinho. H. D. M., Menezes, I. R. A., Zengin. G., Aktumsek, A., \& Quintans-Júnior, L. J. (2016). Evidence for the involvement of TNF- $\alpha$ and IL-1ß in the antinociceptive and anti-inflammatory activity of Stachys lavandulifolia Vahl. (Lamiaceae) essential oil and (-)- $\alpha$-bisabolol, its main compound, in mice. Journal Ethnopharmacology, 15(191), 9-18. https:// doi.org/ 10.1016/j.jep.2016.06.022

Bergman, M. E., Davis, B., \& Phillips, M. A. (2019). Medically Useful Plant Terpenoids: Biosynthesis, Occurrence, and Mechanism of Action. Molecules, 24(21), 3961. https://doi.org/ 10.3390/ moléculas24213961.

Biniecka, M., Kennedy, A., Fearon, U., Ng, C. T., Veale, D. J., \& O'Sullivan, J. N. (2010). Oxidative damage in synovial tissue is associated with in vivo hypoxic status in the arthritic joint. Annals Rheumatic Diseases, 69,1172-1178. http://dx.doi.org/10.1136/ard.2009.111211

Brasil (2016). Ministério da Saúde. Secretaria de Ciência, Tecnologia e Insumos Estratégicos. Departamento de Assistência Farmacêutica. Política e Programa Nacional de Plantas Medicinais e Fitoterápicos / Ministério da Saúde, Secretaria de Ciência, Tecnologia e Insumos Estratégicos, Departamento de Assistência Farmacêutica. - Brasília: Ministério da Saúde. https://bvsms.saude.gov.br/bvs/publicacoes/politica_programa_nacional_plantas_medicinais_fitoterapicos.pdf

Cambui, Y. R. S., \& Natali, M. R. M. (2015). Doenças inflamatórias intestinais: revisão narrativa da literatura. Revista Da Faculdade De Ciências Médicas De Sorocaba, 17(3), 116-119.

Carstens, E., Kuenzler, N., \& Handwerker, H. O. (1998). Ativação de neurônios no subnúcleo caudal do trigêmeo de rato por diferentes produtos químicos irritantes aplicados à mucosa oral ou ocular. Journal Neurophysiology, 80(2), 465-492.

Carvalho, R. C., Maglioni, C. B., Machado, G. B., de Araújo, J. E., da Silva, J. R. T. \& da Silva, M. L. (2018). Prevalence and characteristics of chronic pain in Brazil: a national internet-based survey study Prevalência e características da dor crônica no Brasil: um estudo nacional baseado em questionário pela internet. BrJP, 1(4), 331-338. https://doi.org/10.5935/2595-0118.20180063

Cavalcante, H. A. O., Silva-Filho, S. E., Wiirzler, L. A. M.., Cardia, G. F. E., Uchida, N. S., Silva-Comar, F.M. S., Bersani-Amado, C.A., \& Cuman, R. K. N. (2020). Effect of (-)- $\alpha$-Bisabolol on the Inflammatory Response in Systemic Infection Experimental Model in C57BL/6 Mice. Inflammation, 43(1), 193-203. https://doi.org/10.1007 / s10753-019-01109-8

Costa, E. F. S., \& Dias, G. A. C. (2013). The pathogenesis of asthma. Revista HUPE, 12(2), 31-40. 
D'Almeida, A., Pacheco de Oliveira, M. T., de Souza, É. T., de Sá Coutinho, D., Ciambarella, B. T., Gomes, C. R., Terroso, T., Guterres, S. S. Pohlmann, A.R.., Silva, P.M., Martins, M. A., \& Bernardi, A. (2017). $\alpha$-bisabolol-loaded lipid-core nanocapsules reduce lipopolysaccharide-induced pulmonary inflammation in mice. International Journal of Nanomedicine, 12, 4479-4491. https://doi.org/ 10.2147 / IJN.S130798.

Del Ré, P. V., \& Jorge, N. (2012). Spices as natural antioxidants: their application in food and implication for health. Revista Brasileira de Plantas medicinais, 14(2), 389-399. https://doi.org/10.1590/S1516-05722012000200021

Felipe, L. O., \& Bicas, J. L. (2017). Terpenos, aromas e a química dos compostos naturais. Química nova escola, 39(2), 120-130.

Fernandes, M. Y. D., Carmo, M. R. S. D., Fonteles, A. A., Neves, J. C. S., Silva, A. T. A. D., Pereira, J. F., Ferreira, E. O., Lima, N. M. R., Neves, K. R, \& Andrade, G. M. (2019). (-)- $\alpha$-bisabolol prevents neuronal damage and memory deficits through reduction of proinflammatory markers induced by permanent focal cerebral ischemia in mice. European Journal of Pharmacology, 842, 270-280.https://doi.org/10.1016/ j. ejphar.2018.09.036

Figueiredo, C. R. L. V. (2019). The unusual paradox of cancer-associated inflammation: an update.Journal Brasilian Patology Medicine Laboratory. 2019; 55(3), 321-332. https://doi.org/10.5935/1676-2444.20190029

Fontinele, L. L., Heimfarth, L., Pereira, E. W. M., Rezende, M. M., Lima, N. T.,Carvalho, Y. M. B. G., Pires, E. A. M., Guimarães, A. G., Carvalho, M. T. B., Barreto, R. S. S., Campos, A. R., Antoniolli, A. R., Araújo A. A. S., Quintans-Júnior, L. J., \& Quintans J. S. S. (2019). Anti-hyperalgesic effect of (-)- $\alpha$ bisabolol and (-)- $\alpha$-bisabolol/ $\beta$-Cyclodextrin complex in a chronic inflammatory pain model is associated with reduced reactive gliosis and cytokine modulation. Neurochemistry International, 2019, 131, 104530.https://doi.org/10.1016 / j. neuint.2019.104530

Frikeche, J., Couteau, C., Roussakis, C., \& Coiffard, L. J. (2015). Research on the immunosuppressive activity of ingredients contained in sunscreens. Arch Dermatology Research, 307(3), 211-8. https://doi.org/10.1007/s00403-014-1528-9

Fu, J., Li, F. H., Li, C. K., Li, B. M., Chen, R. Y., \& Kang, J. (2019). Reviews on natural monocyclic sesquiterpenoids and their bioactivities. Zhongguo Zhong Yao Za Zhi, 44(17), 3672-3683.http://doi:.org/10.19540/ j.cnki.cjcmm.20190415.201

Germolec, D. R., Shipkowski, K. A., Frawley, R. P., \& Evans, E. (2018). Markers of Inflammation. Methods in Molecular Biology, 1803, 57-79.

Glavin, G.B., \& Szabo, S. (1992). Experimental gastric mucosal injury: laboratory models reveal mechanisms of pathogenesis and new therapeutic strategies. The FASB Journal, 6, 825-831.https://doi.org/10.1007 / 978-1-4939-8549-4_5.

Hu, S., Ma, Y. L., Guo, J. M., Wen, Q., Yan, G., Yang, S., Fu, Y. H., \& Liu, Y. P. (2020). Bisabolane sesquiterpenes from Clausena sanki with their potential anti-inflammatory activities. Nat ural Prod uct Research, 34(24), 3499-3505. https://doi.org/10.1080/14786419.2019.1582042

Hussain, T., Tan, B., Yin, Y., Blachier, F., Tossou, M. C., \& Rahu, N. (2016). Oxidative Stress and Inflammation: What Polyphenols Can Do for Us? Oxidative Medicine and Cellular Longevity, 7432797. https://doi.org//10.1155 / 2016/7432797

Hussien, Y. A., Abdalkadim, H., Mahbuba, W., Hadi, N. R., Jamil, D. A., \& Al-Aubaidy, H. A. (2020). The Nephroprotective Effect of Lycopene on Renal Ischemic Reperfusion Injury: A Mouse Model. Indian Journal of Clinical Biochemistry, 35(4), 474-481. https://doi.org/10.1007 / s12291-019-00848-7

$\mathrm{J}$

acob, S.E., Matiz, C., \& Herro, E. M. (2011). Compositae-associated allergic contact dermatitis from bisabolol. Dermatitis, 22(2), 102-105.

Javed, H., Meeran, M. F. N., Azimullah, S., Bader Eddin, L., Dwivedi, V. D., Jha, N. K., \& Ojha, S. (2020). $\alpha$-Bisabolol, a Dietary Bioactive Phytochemical Attenuates Dopaminergic Neurodegeneration through Modulation of Oxidative Stress, Neuroinflammation and Apoptosis in Rotenone-Induced Rat Model of Parkinson's disease. Biomolecules, 10(10), 1421. https://doi.org/10.3390 / biom10101421

Jadoon, S., Karim, S., Bin Asad, M. H., Akram, M. R., Khan, A. K., Malik, A., Chen, C., \& Murtaza, G. (2015). Anti-Aging Potential of Phytoextract LoadedPharmaceutical Creams for Human Skin Cell Longetivity. Oxidative Medicine and Cellular Longevity, 709628.https:// doi.org/10.1155/2015/709628

Kamatou, G. P., Makunga, N. P., Ramogola, W. P., \& Viljoen, A. M. (2008). South African Salvia species: a review of biological activities and phytochemistry. Journal of Ethnopharmacology,119(3), 664-672. https://doi.org/10.3390 / biom10101421

Kim, S., Jung, E., Kim, J. H., Park, Y. H.., Lee, J., \& Park, D. (2011). Inhibitory effects of (-)- $\alpha$-bisabolol on LPS-induced inflammatory response in RAW264.7 macrophages. Food Chemistry Toxicology, 49(10), 2580-2585. https://doi.org/10.1016/ j.fct.2011.06.076

Kirsch-Volders, M., Bolognesi, C., Ceppi, M., Bruzzone, M., \& Fenech, M. (2020). Micronuclei, inflammation and auto-immune disease. Mutatation Research Reviews Mutatation Researc, 786,108335. https://doi.org/10.1016/j.mrrev.2020.108335

Kumar, V., Abbas, A., Fausto, N. (2016). Robbins e Cotran - Patologia - Bases Patológicas das Doenças. Elsevier.

Lampropoulou, V., Sergushichev, A., Bambouskova, M., Nair, S., Vincent, E. E., Loginicheva, E., Cervantes-Barragan, L., Ma, X., Huang, S. C., Griss, T., Weinheimer, C. J., Khader, S., Randolph, G. J., Pearce, E. J., Jones, R. G., Diwan, A., Diamond, M. S., \& Artyomov, M. N. (2016). Itaconate Links Inhibition of Succinate Dehydrogenase with Macrophage Metabolic Remodeling and Regulation of Inflammation. Cell Metabolism, 12:24(1), 158166.https://doi.org/10.1016/j.cmet.2016.06.004

Lee, J., Jun, H., Jung, E., Ha, J., \& Park, D. (2010). Whitening effect of alpha-bisabolol in Asian women subjects. International Journal Cosmetetic Science., 32(4), 299-303. https://doi.gov/ 10.1111/j.1468-2494.2010.00560. x.

Leite, G. O., Ecker, A., Seeger, R. L., Krum, B. N., Lugokenski, T. H., Fachinetto, R., Sudati, J. H., Barbosa, N. V., \& Wagner, C. (2018). Protective effect of (-)- $\alpha$-bisabolol on rotenone-induced toxicity in Drosophila melanogaster. Canadian Journal of Physiology and Pharmacology, 96(4), 359-365. https://doi.org/10.1139/ cjpp-2017-0207

Leite, G. O., Leite, L. H., Sampaio, R. S., Araruna, M. K., de Menezes, I. R., da Costa, J. G., \& Campos A. R. (2011). (-)- $\alpha$-Bisabolol attenuates visceral nociception and inflammation in mice. Fitoterapia, 82 (2), 208-211. https://doi.org/10.1016/ j. fitote.2010.09.012 
Leite, G. O., Fernandes, C. N., de Menezes, I. A., da Costa, J. G. M., \& Camposet. A. R. (2012). Attenuation of visceral nociception by $\alpha$-bisabolol in mice: investigation of mechanisms. Organic and Medical Chemistry Letters, 2, 18. https://doi.org/10.1186\%2F2191-2858-2-18

Leong, H. J., Jang, I., Hyun, K. S., Jung, S. K., Hong, G. H., Jeong, H. A., \& Oh, S. G. (2016). Preparation of alpha-bisabolol and phenylethyl resorcinol/TiO2 hybrid composites for potential applications in cosmetics. International Journal Cosmetic Sci.ence, 38(5),524-34. https://doi.org/10.1111/ics.12339

Licari, A., Ruffinazzi, G., DE Filippo, M., Castagnoli, R., Marseglia, A., Agostinis, F., Puviani, M., Milani, M., \& Marseglia, G.L. (2017). A starch, glycyrretinic, zinc oxide and bisabolol based cream in the treatment of chronic mild-to-moderate atopic dermatitis in children: a three-center, assessor blinded trial. Minerva Pediatrics, 69(6), 470-475. https://doi.org/10.23736/S0026-4946.17.05015-0

Lorena, O. F., \& Bicas, J. L. (2017). Terpenos, aromas e a química dos compostos naturais.Química.Nova na Escola, 39 (2), 120-130. http://doi.org/10.21577/0104-8899.20160068.

Luqman, S., \& Srivastava, S. (2012). Protective effect of (-) $\alpha$-bisabolol on markers of oxidative stress in erythrocytes subjected to oxidative insult. Natural Precedings. https://doi.org/10.1038/npre.2012.6903.1

Marco, C A., Santos, H. R, Feitosa, A. G. S., Feitosa, J. A., \& Costa, J. G. M. (2015). Teor, rendimento e qualidade do óleo essencial de Vanillosmopsis arbórea (Gardner) Baker (candeeiro) e sua ação alelopática. Revista Cubana de Plantas Medicinales, 20(1), $131-141$.

Maurya, A K., Singh, M., Dubey, V., Srivastava, S. Luqman, S., \& Bawankule, D. U. (2014). $\alpha$-(-)-bisabolol reduces pro-inflammatory cytokine production and ameliorates skin inflammation. Current Pharmaceutical Biotechnology, 15(2):173-181. https:/doi.org/10.2174 / 1389201015666140528152946

McGarry, T., Biniecka, M., Veale, D., \& Fearon, U. (2018). Hypoxia, Oxidative Stress and Inflammation, Free Radical Biology and Medicine, $125,15-24$. https:/doi.org/10.1016/j. freeradbiomed.2018.03.042

Medzhitov, R. (2010). Inflammation 2010: New Adventures of an Old Flame. Cell, 140(6), 771-776. https://doi.org/10.1016/j. cell.2010.03.006.

Medzhitov, R. (2008). Origin and physiological roles of inflammation. Nature, 454, 428-435. https//:doi.org/10.1038/nature07201

Melo, LT., Panchalingam, V., Cherkas, P., Campos, A. R., Avivi-Arber, L., \& Sessle, B. J. (2019). (-)- $\alpha$-Bisabolol reduces nociception and trigeminal central sensitisation in acute orofacial neuropathic pain induced by infraorbital nerve injury. Life Sciences, 227, 122-128.https://doi.org/10.1016/j.lfs.2019.04.032

Miraj, S., \& Alesaeidi, S. (2016). A systematic review study of therapeutic effects of Matricaria recuitta chamomile (chamomile). Electron Physician, 8(9), 3024-3031. https://doi.org/ 10.19082 / 3024

Muñoz-Pérez, V. M., Ortiz, M. I., Ponce-Monter, H. A., Monter-Pérez, V., \& Barragán-Ramírez, G. (2018). Anti-inflammatory and utero-relaxant effect of $\alpha$ bisabolol on the pregnant human uterus. Korean Journal Physiology Pharmacology, 22(4), 391-398. https://doi.org/10.4196 / kjpp.2018.22.4.391

Nóbrega, A.T., Wagemaker, T. A. L., \& Maia Campos, P. M. B. G. (2013). Antioxidant activity of Matricaria chamomilla L. extract and clinical efficacy of cosmetic formulations containing this extract and its isolated compounds. Biomedical and Biopharmaceutical Research, (10) 2, 249261.https://doi.org/10.19277 / BBR.10.2.69

Ojha, S., Azimullah, S., Al Taee, H., \& Meeran, M. F. N. (2017). Cardioprotective effect of (-)- $\alpha$-Bisabolol in animal model of myocardial infarction. Planta Medica International Open, 4(s01), S1- S202.https://doi.org/10.1055/s-0037-1608133

Ortiz, M. I., Cariño-Cortés, R., Ponce-Monter, H. A., Castañeda-Hernández, G., \& Chávez-Piña, A. E. (2018). Pharmacological interaction of $\alpha$-bisabolol and diclofenac on nociception, inflammation, and gastric integrity in rats. Drug Development Research, 79(1), 29-37. https://doi.org/10.1002 / ddr.21418

Pacífico, D. M., Araújo, T. S. L., Sousa, N. A., Costa,Souza, L. K. M., Pereira Júnior, J. L., \& Medeiros, J. V. R. (2018). Scientific and technological forecasting of matricaria recutita 1. (chamomile). Revista Gestão, Inovação e Tecnologias, 8(2), 4339-4356. https://doi.org./10.7198/geintec.v8i2.773

Page, M. J., McKenzie, J. E., Bossuyt, P. M., Boutron, I., Hoffmann, T.C, \& Mulrow, C. D. (2021). The PRISMA 2020 statement: an updated guideline for reporting systematic reviews. $B M J, 372(71)$.

Moura Rocha, N. F., Venâncio, E. T., Moura, B. A., Gomes Silva, M. I., Aquino Neto, M. R., Vasconcelos Rios, E. R., de Sousa, D. P., Mendes Vasconcelos, S. M., de França Fonteles, M. M., \& de Sousa, F. C. (2010). Gastroprotection of (-)-alpha-bisabolol on acute gastric mucosal lesions in mice: the possible involved pharmacological mechanisms. Fundamental \& Clinical Pharmacology, 24(1),63-71. https:// doi.org/10.1111/j.1472-8206.2009. 00726.x

Repetto, M. G., \& Llesuy, S. F. (2002). Antioxidant properties of natural compounds used in popular medicine for gastric ulcres. Brasilian Journal of Medical and Biological Research, 35,523-534.

Rocha, N. F. M., Oliveira, G. V., Araújo, F. Y. R., Rios, E. R. V., Carvalho, A. M. R., Vasconcelos, L. F., Macêdo, D. S., Soares, P. M. G., De Sousa, D. P., \& de Sousa, F. C. F. (2011). (-)- $\alpha$-Bisabolol-induced gastroprotection is associated with reduction in lipid peroxidation, superoxide dismutase activity and neutrophil migration, European Journal of Pharmaceutical Sciences, 44(4), 455-461. https://.doi.org/10.3390\%2Fantibiotics9010028

Rocha, N. F.; Rios, E. R.; Carvalho, A. M.; Cerqueira, G. S.; Lopes Ade, A.; Leal, L. K.; Dias, M. L.; de Sousa, D. P., \& de Sousa, F. C. (2011). Antinociceptive and anti-inflammatory activities of (-)- $\alpha$-bisabolol in rodents. Naunyn Schmiedebergs Arch Pharmacology, 384(6), 525-533. https://doi.org/10.1007 / s00210-011-0679-x

Romagnoli C., Baldisserotto, A., Malisardi, G., Vicentini, C. B., Mares, D., Andreotti, E., Vertuani. S., \& Manfredini, S. (2015). A Multi-Target Approach toward the Development of Novel Candidates for Antidermatophytic Activity: Ultrastructural Evidence on $\alpha$-Bisabolol-Treated Microsporum gypseum. Molecules, 20(7):11765-, 76. https:// doi.gov/10.3390/molecules200711765

Russell, K. \& Jacob, S. E. (2010). Bisabolol. Dermatitis, 21(1), 57-58. 
Sampaio, T. L., Menezes, R. R., da Costa, M. F., Meneses, G. C., Arrieta, M. C., Chaves Filho, A. J., de Morais, G. B., Libório, A. B., Alves, R. S., Evangelista, J. S., \& Martins, A. M. (2016). Nephroprotective effects of (-)- $\alpha$-bisabolol against ischemic-reperfusion acute kidney injury, Phytomedicine, 23(14), 1843-1852. https://doi.org/10.1016/j.phymed.2016.11.008

Schweiger, D., Schoelermann, A. M., Filbry, A., Hamann, T., Moser, C., \& Rippke, F. (2015). Highly efficient and compatible shampoo for use after hair transplant. Clinical Cosmetic Investigational Dermatology, 8, 355-60. https://doi.org/10.2147/CCID.S86015

Sharifi-Rad, J., Sureda, A., Tenore, G., Daglia, M., Sharifi-Rad, M., Valussi, M., Tundis, R., Sharifi-Rad, M., Loizzo, M., \& Ademiluyi, A. (2017). Biological Activities of Essential Oils: From Plant Chemoecology to Traditional Healing Systems. Molecules, 22 (1), 70. https://doi.org/10.3390\%2Fmolecules22010070

Sharifi-Rad, M., Nazaruk, J., Polito, L., Morais-Braga, M. F. B., Rocha, J. E., Coutinho, H. D. M., Salehi, B., Tabanelli, G., Montanari, C., Del Mar Contreras, M., Yousaf, Z.; Setzer, W. N., Verma, D. R., Martorell, M., Sureda, A., \& Sharifi-Rad, J. (2018). Matricaria genus as a source of antimicrobial agents: From farm to pharmacy and food applications. Microbiological Research, 215, 76-88. https://doi.org/10.1016/j.micres.2018.06.010

Silva, E. D. F., \& Dias, G. A. C. (2013). Patogenia da asma. Revista do Hospital Universitário Pedro Ernesto,12(2), 31-40. https://.doi.org/10.12957/rhupe.2013.8485

Singh, N., Baby, D., Rajguru, J. P., Patil, P. B., Thakkannavar, S. S., \& Pujari, V. B. Inflammation and cancer. Annals of African Medicine, $18(3)$, $121-126$. https://doi.org/10.4103/aam.aam_56_18

Solovăstru, L. G., Stîncanu, A., De Ascentii, A., Capparé, G., Mattana, P. \& Vâță, D. (2015). Randomized, controlled study of innovative spray formulation containing ozonated oil and $\alpha$-bisabolol in the topical treatment of chronic venous leg ulcers. Advances in Skin \& Wound Care, 28(9), 406-409. https://doi: 10.1097 / 01.ASW.0000470155.29821.ed.

Souza, M. T., Silva, M. D., \& Carvalho, R. (2010). Integrative review: what is it? How to do it? Einstein,8(1), 102-106. https://doi.org/10.1590/S167945082010RW1134

Tanini, S., Calabrese, S., Fisher, A. D., Maggi, M., \& Lo Russo, G. (2020). When Testosterone Needs to be Contrasted: A Preliminary Study of Scar Prevention in Transmen Top Surgery with an Innovative Galenic Preparation. Aesthetic Plastic Surgery, 44(3), 1006-1013. https;//doi.org/10.1007 / s00266$020-01678-2$

Teixeira, G. F. D., Vieira-Neto, A. E., a Costa, F. N., Silva, A. R. A., \& Campos, A. R. (2017). Antinociceptive effect of (-)- $\alpha$-bisabolol in nanocapsules. Biomedicine Pharmacotherapy, 91, 946-950. https://doi.org/10.1016/j.biopha.2017.05.024

Teixeira, G. F., Costa, F. N., \& Campos, A. R. (2017). Corneal antinociceptive effect of (-)- $\alpha$-bisabolol. Pharmaceutical Biology, 55(1), 1089-1092. https://doi.org/10.1080/ 13880209.2017.1285944

Tholl, D. (2015). Biosynthesis and biological functions of terpenoids in plants. Advances in Biochememical Engineering/ Biotechnology, 48, 63-106. https://doi.org/10.1007/10_2014_295

Torres-González, L., Cienfuegos-Pecina, E., Perales-Quintana, M. M., Alarcon-Galvan, G., Muñoz-Espinosa, L. E., Pérez-Rodríguez, E., \& Cordero-Pérez, P. (2018). Nephroprotective Effect of Sonchus oleraceus Extract against Kidney Injury Induced by Ischemia-Reperfusion in Wistar Rats. Oxidative Medicine and Cellular Longevity, 2018, 9572803. https://doi.org/10.1155 / 2018/9572803

Wallace, J. L. (2008). Prostaglandns, NSAIDs, and gastric mucosal protection: why doens't the stomach digest itself? Physiological Reviews, 88, 1547-1565.

Werner, M., Herling, M.; Garbe, B., Theek, C., Tronnier, H., Heinrich, U., \& Braun, N. (2017). Determination of the Influence of the Antiphlogistic Ingredients Panthenol and Bisabolol on the SPF Value in vivo. Skin Pharmacology and Physiology, 30(6), 284-291. https://doi.org/10.1159/000480301

Xiao, M., Zhong, H., Xia, L., Tao, Y., \& Yin, H. (2017). Pathophysiology of mitochondrial lipid oxidation: Role of 4-hydroxynonenal (4-HNE) and other bioactive lipids in mitochondria. Free Radical. Biology \& Medicine, 111, 316-327. https://doi.org/10.1016/ j. freeradbiomed.2017.04.363

Xu, C., Sheng, S., Dou, H., Chen, J., Zhou, K., Lin, Y., \& Yang, H. (2020). $\alpha$-Bisabolol suppresses the inflammatory response and ECM catabolism in advanced glycation end products-treated chondrocytes and attenuates murine osteoarthritis. International Immunopharmacology,84, 106530. https://doi.org/10.1016/ j. intimp.2020.106530 